\title{
Morfologia polínica da tribo Protieae (Burseraceae) na América do Sul ${ }^{1}$
}

\author{
CLARA ISABEL AGUILAR-SIERRA² e THEREZINHA SANT’ANNA MELHEM ${ }^{3}$
}

(recebido em 02/05/96; aceito em 10/06/97)

\begin{abstract}
Pollen morphology of the tribe Protieae (Burseraceae) in South America). The tribe Protieae is represented in South America by the genera: Crepidospermum Hook. f., Protium Burm. f. and Tetragastris Gaertn. Crepidospermum comprises five species distributed mainly in Amazonia. Protium is a neotropical genus of approximately 146 species. Tetragastris is found almost exclusively in lowland moist forests in Central America, northern South America and parts of the Caribbean. Pollen grains from 177 collections representing 51 taxa were examined. The pollen material was acetolyzed, measured, described and photographed by light microcopy and, in most cases, also by electron microscopy scanning. The data obtained was statistically analysed by methods according the sample sizes. Pollen grains of Crepidospermum and Tetragastris are of the same intermediate size, being mostly subprolate with a triangular ambit, longicolpate, and psilate which indicates the stenopalynous nature of these genera. In Crepidospermum the species can be distinguished by the various characteristics of the apertures; the Tetragastris species studied are very similar in their pollen grains and were indistinguishable. Protium is diverse in the form of the pollen grains (spheric, prolate-spheroid, subprolate, prolate) and in the ornamentation of the exine (psilate, perforate, striate, micro-reticulate). Also as regards the polar diameter, the form and size of the endoaperture, the size of the colpus, the ornamentation of the colpus membrane, and the thickness of the exine, the studied species differed. These observations confirm that Protium is an euripalynous genus, in which, in most cases, the morphology of the pollen grain could support the taxonomic separation of species.
\end{abstract}

RESUMO - (Morfologia polínica da tribo Protieae (Burseraceae) na América do Sul). A tribo Protieae está representada na América do Sul pelos gêneros: Crepidospermum Hook. f., Protium Burm. f. e Tetragastris Gaertn. Crepidospermum compreende cinco espécies distribuídas principalmente na Amazônia. Protium é um gênero neotropical com aproximadamente 146 espécies. Tetragastris encontrase quase que exclusivamente em altitudes baixas, nas florestas úmidas da América Central, norte da América do Sul e algumas partes do Caribe. Foram examinados os grãos de pólen de 177 exsicatas que representam 51 táxons. O material polínico foi acetolisado, medido, descrito e fotografado sob microscopia óptica e, na maioria dos casos, também em microscopia eletrônica de varredura. As medidas receberam tratamento estatístico adequado ao tamanho da amostra. As espécies de Crepidospermum e Tetragastris apresentam grãos de pólen médios, principalmente subprolatos, âmbito triangular, longicolpados, psilados, indicando a condição estenopolínica dos gêneros. As características das aberturas permitiram diferençar as espécies de Crepidospermum entre si; enquanto as espécies consideradas de Tetragastris são muito similares não permitindo sua separação. Protium é variável na forma (esférica, prolata-esferoidal, subprolata, prolata) e na ornamentação da exina (psilada, psilado-perfurada, estriada, microrreticulada); as medidas do diâmetro polar, a forma e o tamanho da endoabertura, o tamanho do colpo, a ornamentação da membrana do colpo e as medidas da espessura da exina também são características que poderão ser usadas para distinguir os táxons. Estas observações assinalam que Protium é um gênero euripolínico, de modo que a morfologia polínica pode, em muitos casos, subsidiar a delimitação taxonômica das espécies.

Key words - Burseraceae, Crepidospermum, Protium, Tetragastris, pollen grains

\section{Introdução}

A tribo Protieae está distribuída principalmente nos trópicos americanos onde compreende os gêneros Crepidospermum Hook. f., Protium Burm. f. e Tetragastris Gaertn. Crepidospermum cresce nas florestas úmidas tropicais de altitudes baixas das regiões situadas ao leste dos Andes, da Colômbia até as Guianas, Venezuela, Brasil e Bolívia; menos freqüentemente em florestas de terras alagadiças,

1. Parte da tese de doutorado de C.I. Aguilar-Sierra, Departamento de Botânica, IB-USP.

2. Universidad Nacional de Colombia, Facultad de Ciencias, A.A. 3840 Medellín, Colombia. Bolsista da RLB e do Programa Mutis.

3. Instituto de Botânica, Caixa Postal 4005, 01061-970 São Paulo, Brasil. Bolsista do CNPq. florestas de dossel baixo sobre areia branca e florestas secundárias (Cuatrecasas 1957, Daly 1987a). Das cinco espécies reconhecidas por Daly (1987a), $C$. cuneifolium (Cuatrec.) Daly parece ser endêmica da região amazônica (parte mais alta do rio Negro); $C$. goudotianum (Tul.) Tr. \& P1. e C. rhoifolium (Benth.) Tr. \& P1., com uma distribuição geográfica mais ampla e sobreposta, podem ocupar diferentes habitats; C. goudotianum parece estar pobremente representada nas Guianas e na Venezuela, porém ambas estão difundidas na Amazônia, alcançando o oeste da Colômbia; C. multijugum Swart, muito próxima à última espécie mencionada, aparentemente foi coletada apenas duas vezes e pode representar uma forma aberrante de C. goudotianum; C. prancei Daly tem uma ampla distribuição na Amazônia Central e Ocidental. 
Protium é um gênero com aproximadamente 146 espécies, das quais só nove não são neotropicais; são árvores das florestas úmidas tropicais, sendo a Amazônia seu centro primário de diversidade, onde encontram-se cerca de 73 espécies, 42 das quais são endêmicas; os centros secundários são Guayana (Venezuela), as Guianas, o Chocó (do sul do Panamá até Esmeraldas no Equador), o sul da América Central e a Mata Atlântica no Brasil (Daly 1992a).

Ao redefinir os limites genéricos da tribo Protieae, Daly (1989) concluiu que Paraprotium Cuatrec. era um grupo polifilético que devia ser colocado dentro de Protium e apresentou outras características para reforçar a separação que, tradicionalmente, tem sido feita entre Crepidospermum, Protium e Tetragastris. Daly (1992a) afirmou que dentro do gênero Protium podem ser identificados, pelo menos, nove grupos naturais e que a revisão do gênero, em preparação por este autor, fornecerá dados sobre a anatomia foliar, tipos de pseudo-arilos e de embriões, padrões de germinação e outros caracteres que poderão conduzir à segregação de alguns desses grupos naturais como novos gêneros. Daly (1992b) revisou as Burseraceae da Mata Atlântica do Brasil que apresentam problemas taxonômicos ainda não resolvidos e descreveu duas espécies novas de Protium, $P$ bahianum Daly e $P$ icicariba (DC.) March. var. talmonii Daly, que se encontram em sério perigo de extinção.

O gênero Tetragastris, estreitamente relacionado com Protium, encontra-se quase exclusivamente em altitudes baixas, nas florestas úmidas da América Central, norte da América do Sul e algumas partes do Caribe (Daly 1990). Este autor reconheceu nove espécies para o gênero; destas, T. panamensis (Engl.) Kuntze, apresenta a maior distribuição, estendendose desde Belize e Guatemala através de uma grande área do norte da América do Sul; numa extensa área é simpátrica com T. altissima (Aubl.) Swart e a separação de seus nichos não é conhecida até agora. Nas partes baixas do norte da Venezuela e da Colômbia encontra-se T. mucronata (Rusby) Swart; T. hostmannii (Engl.) Kuntze é essencialmente uma espécie das Guianas, ainda que coletada também no norte do Pará e no Amapá (Brasil) assim como no norte de Bolívar (Venezuela). Três espécies distribuem-se no leste do Brasil, T. breviacuminata Swart (Rio de Janeiro), T. catuaba Cunha (Babia, Pernambuco) e T. occhionii (Rizzini) Daly (Daly 1990).
Não há na literatura dados sobre a morfologia polínica de espécies de Crepidospermum; para Protium há informação nos trabalhos de Erdtman (1952), Carreira (1976), Daly (1987b), Roubik \& Moreno (1991), Segaar \& van der Ham (1993) e Barros \& Barth (1994) e para Tetragastris em Roubik \& Moreno (1991).

Este estudo pretende caracterizar morfologicamente os grãos de pólen de 51 táxons da tribo Protieae: Crepidospermum (4), Protium (45) e Tetragastris (2), ocorrentes na América do Sul. Busca-se ampliar a escassa informação palinológica da família no Neotrópico, bem como determinar até onde as características polínicas podem ajudar na delimitação dos táxons.

\section{Material e métodos}

O material polínico foi coletado de botões florais das seguintes exsicatas, sendo assinalada com um asterisco (*) aquela selecionada como material padrão; na relação de exsicatas estudadas, sempre que não constar o nome do determinador significa que os materiais foram identificados por D. Daly:

Crepidospermum cuneifolium (Cuatrec.) Daly [=Hemicrepidospermum cuneifolium Cuatrec.]. Colômbia: Amazonas: Río Caquetá, Araracuara, T. Van Andel et al. 344, IX- 1989, det. M. Sánchez (COAH)*. C. goudotianum (Tul.) Tr. \& Pl. Brasil: Mato Grosso, W. Thomas et al. 4042, IX-1985 (INPA). Pará: Tucuruí, D. Daly et al. 1320, XI-1981 (MG); D. Daly et al. 1477, XI-1981 (INPA); Macabá, Carajás, U.N. Maciel et al. 718, VIII1982 (INPA). Colômbia: Meta: El Mico, W.R. Philipson et al. 1377, XI-1949, det. J. Cuatrecasas, conf. D. Daly (COL)*; Sierra de La Macarena, Bocas del Río Sansa, J.M. Idrobo, R. Jaramillo 2128, III-1956 (COL).Vaupés: Caño Grande, J. Cuatrecasas 7374, XI-1939, det. J. Swart, conf. D.Daly (COL). C. prancei Daly. Colômbia: Amazonas: Rio Caquetá, Araracuara, H. Vester et al. 683, X-1991 (COAH)*. C. rhoifolium (Benth.) Tr. \& Pl. [=Hemicrepidospermum rhoifolium (Benth.) Swart]. Brasil: Amazonas: Manaus, W. Rodrigues, J. Lima 2345, VIII-1961 (INPA); Porto Velho, M.F. Silva et al. 596, VII-1972 (INPA); Rio Purus, G.T. Prance et al. 13752, VI-1971 (INPA). Pará: Oriximiná, C.A. Cid Ferreira et al. 1837, VIII-1980 (INPA); C.A. Cid Ferreira et al. 2298, IX-1980 (INPA). Rondônia: Rio Jarú, A.P. Duarte 7052, IX-1962 (INPA). Colômbia: Antioquia: AnoríProvidencia, D.D. Soejarto et al. 3927, V-1973 (HUA)*. Valle: Buenaventura, Bajo Calima, D. Daly et al. 5980, V-1 989 (HUA). Protium altsonii Sandw. Brasil: Amazonas: Manaus, F.C. Mello s.n., IX-1955 (INPA)*. P. amplum Cuatrec. Colômbia: Chocó: Alto Río Baudó, C. La Rotta, H. Martínez 686, VI-1985 (COL)*. Valle: Buenaventura, Bajo Calima, A. Gentry et al. 57032, IV1987, det. D. Faber-Langendoen (CUVC). P. apiculatum Swart. Brasil: Amapá: Macapá, B.V. Rabelo, R. Cardoso 3154, I-1985 (MG). Amazonas: Presidente Figueiredo, C.A. Cid Ferreira et al. 8227, IX-1986 (INPA); Reserva Genética do Jarí, M.J. Pires, N. Silva 1470, X-1986 (INPA)*; M.J. Pires, N. Silva 1471, X1986 (INPA). Pará: Almeirim, M.J. Pires, N. Silva 1481, XI-1986 (MG). P. aracouchini (Aubl.) March. Brasil: Amazonas: Humaitá, L.O.A. Teixeira et al. 1210, VI-1982 (INPA). Rondônia: Porto 
Velho, W. Thomas et al. 5152, VI-1986 (INPA). Colômbia: Antioquia: Turbo, O. Haught 4588, IV-1945, det. Killip, conf. D. Daly (COL)*; Mutatá, J. Brand, E. Ascanio 238, III1983 (HUA); San Luis, Quebrada La Cristalina, J.G. Ramírez, D. Cárdenas 1182, VI-1987, det. J.G. Ramírez, D. Cárdenas, conf. D. Daly (JAUM); J.G. Ramírez, D. Cárdenas 1292, VIl1987, det. J.G. Ramírez, D. Cárdenas, conf. D. Daly (COL). Chocó: Riosucio, D. Cárdenas 1655, IV-1988 (JAUM); D. Cárdenas 1777, IV-1988 (JAUM). P. brasiliense (Spreng.) Engl. Brasil: Mato Grosso: Cuiabá-Porto Velho, C.A. Cid Ferreira et al. 4436, VI-1984 (INPA)*; Rio Aripuanã, C.C. Berg et al. 18401, X-1973 (INPA). Minas Gerais: Serra do Cipó, km 120 rodovia Belo Horizonte-Conceição do Mato Dentro, M.C. Henrique et al. 6627, X-1980, det. J.R. Pirani (SPF); km 107, rodovia Belo Horizonte-Conceição do Mato Dentro, J.R. Pirani et al. 7464, X-1981, det. J.R. Pirani (SPF). Rio de Janeiro: Barra de Tijuca, W. Hoehne 5824, X-1964, det. J.R. Pirani (SPF). P. buenaventurense Cuatrec. Colômbia: Valle: Buenaventura, J. Cuatrecasas 19732 (Isótipo), XI-1945, det. J. Cuatrecasas, conf. D. Daly (COL)*. P. calanense Cuatrec. Colômbia: Antioquia: Zaragoza, Providencia, D.D. Soejarto, J.D. Villa 2787, II-1971, det. D.D. Soejarto, conf. D. Daly (HUA). Santander: Barrancabermeja, O. Haught 2096, VII1936, det. J. Cuatrecasas, conf. D. Daly (COL)*. P. carnosum A.C. Sm. Brasil: Rondônia: Ariquemes, L.O.A. Teixeira et al. 473, V- 1982 (INPA)*; L.O.A. Teixeira et al. 585, V- 1982 (INPA); Guajará-Mirim, C. A. Cid Ferreira 8790, IV-1987 (INPA); Porto Velho, M. Nee 34916, IV-1987 (SP). P. cianipyrenum Cuatrec. Colômbia: Valle: Río Anchicayá, J. Cuatrecasas 14417 (Isótipo), IV-1943, det. J. Cuatrecasas, conf. D. Daly (COL)*; Buenaventura, Bajo Calima, M. Monsalve 1723, IX-1987 (CUVC). P. crassipetalum Cuatrec. Brasil: Amazonas: Presidente Figueiredo, W. Thomas et al. 5303, VII-1986 (INPA); C.A. Cid Ferreira et al. 8089, IX-1986 (INPA); Rio Cuieiras, D.G. Campbell et al. 21923, IV-1974 (INPA). Rondônia: Porto Velho, W. Thomas et al. 5112, VI-1986 (INPA). Colômbia: Guainía: Río Negro, R.E. Schultes, F. López 9312, XII-1947, det. J. Cuatrecasas, conf. D. Daly (COL)*. Peru: D. Daly 5129 (MG). P crenatum Sandw. Guiana: M.J. JansenJacobs et al. 722, XI-1987 (SP)*. Venezuela: Barinas, H. Rodríguez 1534, III-1969 (SP). P. dawsonii Cuatrec. Brasil: Goiás: Rio da Prata, H.S. Irwin et al. 14339, IV-1966, det. D.M. Porter (INPA)*. Mato Grosso, M.G. Silva, C. Rosário 5039, VI-1979 (INPA). P. decandrum (Aubl.) March. Brasil: Amazonas: Manaus, Ponta Negra, W. Rodrigues et al. 4775, XI-1962 (INPA)*; W. Rodrigues et al. 4825, XI-1962 (INPA). Pará: Itinga do Pará, D. Daly et al. 762, X-1980 (INPA); Tucuruí, J. Revilla et al. 8552, X-1983 (INPA); E. Lima et al. 8573, X-1983 (INPA). P. divaricatum Engl. subsp. divaricatum. Brasil: Amazonas: Jutaí, D. Daly et al. 4130, X1986 (US); Lago de Padajós, R.L. Fróes 26400, VIII-1950 (SP). Pará: Porto Trombetas, E. Soares 12, XI-1985 (INPA) Rondônia: Porto Velho, F. Dionízia et al. 88, VIII-1987 (INPA). Colômbia: Amazonas-Vaupés: Río Apaporis, R.E. Schultes, I. Cabrera 14954a, VI-1952 (COL)*. P. divaricatum Engl. subsp. fumarium Daly. Guiana Francesa: Saül, La Fumée Mountain, S. Mori et al. 19181, VIII-1988, (US)*. P. elegans Engl. Brasil: Acre: Cruzeiro do Sul, G.T. Prance et al. 12128, IV-1971 (INPA). Colômbia: Amazonas: Río Caquetá, Araracuara, E. Alvarez et al. 1017, III-1990 (COAH). Valle: Buenaventura, Bajo Calima, A. Gentry et al. 56609, XII1987 (CUVC)*. P. ferrugineum (Engl.) Engl. [=Paraprotium ferrugineum (Engl.) Cuatrec.]. Brasil: Amazonas: Río Cuieiras (Jauarí), G. T. Prance et al. 29437, VII-1985 (SP); Serra Aracá, J. Pipdy et al. 6725, II-1984 (INPA). Rondônia: Porto
Velho, G. Vieira et al. 288, X-1979 (INPA). Colômbia: Amazonas-Vaupés: Río Apaporis, H. García-Barriga 13837, XII-1951 (COL). Valle: Buenaventura, Bajo Calima, M. Monsalve 693, II-1985 (JAUM)*; M. Monsalve 1302, XI1986 (CUVC). P. fimbriatum Swart [=Paraprotium amazonicum Cuatrec.]. Brasil: Amazonas: estrada ManausPorto Velho, G. Vieira et al. 46, IX- 1979 (INPA); Guapichuna, E. Acero, R. Rodrigues 983, II-1979 (INPA); Tefé, J. L. Amaral et al. 141, X-1982 (INPA). Rondônia: Porto Velho, C.D.A. Mota, L. Coêlho 96, IX-1975 (INPA). Colômbia: Vaupés: Miraflores, G. Gutiérrez, R. E. Schultes 798, II1944 (COL)* $^{*}$. P. cf. gallosum Daly. Brasil: Amazonas: Presidente Figueiredo, C.A. Cid Ferreira et al. 8208, IX1986 (US). Colômbia: Amazonas: Río Caquetá, Araracuara, A. C. Londoño et al. $1073(\mathrm{COAH})^{*}$. P. giganteum Engl. Brasil: Amazonas: Presidente Figueiredo, C.A. Cid Ferreira et al. 8080, IX-1986 (INPA)*. P. grandifolium Engl. Brasil: Amazonas: Manaus, W.A. Rodrigues s.n., IX-1955 (INPA); Rio Uatumã, C.A. Cid Ferreirra et al. 787, VIII-1979 (INPA); C.A. Cid Ferreira et al. 788, VIII-1979 (INPA)*. P. guianense (Aubl.) March. subsp. pilosissimum (Engl.) Daly. Brasil: Mato Grosso: Nobres, C.A. Cid. Ferreira et al. 6139, IX-1985 (INPA)*. P. hebetatum Daly. Brasil: Amazonas: Manaus, W. Rodrigues s.n. (INPA)*; D. Coêlho, Hugo s.n., VIII-1981 (INPA); Nova Airão, R. Miller 641, IX- 1989, det. W. Milliken (HITAM); R. Miller 643, IX-1989, det. W. Milliken (HITAM). P. heptaphyllum (Aubl.) March. Brasil: Goiás: Caldas Novas, E.P. Heringer 18629, IX-1982 (SP). Minas Gerais: Serra do Cipó, Vale do Córrego Chapéu do Sol, I. Cordeiro, J.R. Pirani 6528, IX-1980, det. J.R. Pirani (SPF); Ituiutaba, A. Macêdo 734, IX-1945, det. J.R. Pirani (SP). Pará: Monte Alegre, R. L. Fróes 30341, IX-1953, det. M.J. Pires (SP). São Paulo: MojiGuaçú, E.H.A. Rodrigues 62, VIII-1990, det. E.H.A. Rodrigues (SP). Colômbia: Bolívar: Palotal, R. RomeroCastañeda 1696, V-1949, det. R. Romero-Castañeda, conf. D. Daly (COL)*. Caquetá: San Vicente del Caguán, J. Betancur, J. Porras 1512, I-1990 (HUA). Meta: Cumaral, C. Román 62, IV-1985, det. R. Jaramillo, conf. D. Daly (COL). P. insigne (Tr. \& Pl.) Engl. Brasil: Pará: Almeirim, M.R. Santos 514, XII-1978, det. N. A. Rosa (HITAM). Colômbia: Caquetá: Florencia, G. Davidse et al. 5771a, det. R. Liesner (COL)*. Magdalena: Ciénaga, R. Romero-Castañeda 538, IX-1949, det. A. Dugand (MEDEL). P. cf. leptostachyum Cuatrec. Brasil: Amazonas: Manaus, L. Alencar 463 (MG)*. P. llanorum Cuatrec. Colômbia: Vichada: Gaviotas, I. Cabrera 2507, I1973, det. I. Cabrera, conf. D. Daly (COL)*. P macrophyllum (H.B.K.) Engl. Colômbia: Santander: Barrancabermeja, O. Haught 1994, IX-1936, det. J. Swart (COL)*. Valle: Buenaventura, Bajo Calima, M. Monsalve 616, XII-1984, det. M. Monsalve (COL). P minutiflorum Guatrec. Colômbia: Amazonas-Vaupés, Río Apaporis, H. García-Barriga 13898, XII-1951, det. J. Cuatrecasas conf. D. Daly (COL)*. P. neglectum Swart. Bolívia: G.T. Prance et al. 8438, XI-1968, det. W. Rodrigues (INPA). Brasil: Amazonas: Manaus, F. Mello s.n., IX-1955, det. J.C. Lindeman (INPA). Bahia: Ilhéus, CEPEC (Centro de Pesquisas do Cacau), J.L. Hage, E.B. Dos Santos 1389, IX-1981, det. J.R. Pirani (SPF). Colômbia: Magdalena, Santa Marta, R. Romero-Castañeda 558a, XII1947, det. A. Dugand (COL)*. Venezuela: Barinas, F.J. Breteler 3656, X-1964, det. F.J. Breteler (MEDEL). P. nervosum Cuatrec. Colômbia: Cauca: Río Micay, J. Cuatrecasas 14147, II-1943, det. J. Cuatrecasas (COL). Valle: Río Naya, J. Cuatrecasas, 14037 (Isótipo), II-1943, det. J. Cuatrecasas, conf. D. Daly (COL)*; Buenaventura, Bajo Calima, A. Gentry et al. 48012, VII-1984 (CUVC); M. Monsalve 2085 (CUVC). 
P. nitidifolium (Cuatrec.) Daly [=Paraprotium nitidifolium Cuatrec.]. Brasil: Amazonas: Manaus, Santo Antônio de Abamari, G.T. Prance et al. 24289, XI-1976 (INPA)*; km 168 estrada Manaus-Caracaraí (Br-174), G.T. Prance et al. 22671, IX-1974 (INPA); Manaus-Porto Velho, G.T. Prance et al. 22989, 1974 (INPA); Presidente Figueiredo, C.A. Cid Ferreira et al. 8208, IX-1986, det. J. Ramos (INPA). Pará: M.J. Pires, N. Silva 1470 (MG). P. opacum Swart subsp. rabelianum Daly. Brasil: Amapá: Água Azul, J.M. Pires, P.B. Cavalcante 52257, VII-1962 (SP)*. P. ovatum Engl. Brasil: Goiás: Brasília, J.R. Pirani et al. 1635, II-1987, det. J.R. Pirani (SPF); Bacia do Rio São Bartolomeu, E. R Heringer et al. 6397, III-1981, det. B. A. S. Pereira (SPF); Reserva Ecológica do IBGE, M.L.M. Azevedo 50, V-1988, det. R. Mendoça (SPF). Minas Gerais: Gonzalo de Ibaete, Rodovia Br-365, km 261, G. Hatschbach 42802, III-1981, det. J.R. Pirani (SPF)*. Mato Grosso: Bataguaçú, Rodovia Br-267, G. Hatschbach, O. Guimarães 21750, VII-1979, det. J.R. Pirani (SPF). São Paulo: Moji-Guaçú, J. Mattos 12243, V-1965, det. J.R. Pirani (SP); W. Mantovani 1832, V-1981 (SP). P. paniculatum Engl. var. paniculatum. Brasil: Amazonas: Máncio Lima, C.A. Cid Ferreira et al. 5241, X-1984 (INPA)*; Manaus, Rio Negro, G. T. Prance et al. 16019, XII-1971 (INPA). Pará: Porto Trombetas, E. Soares 29, XI-1985 (INPA). Colômbia: Amazonas: Río Caquetá, Araracuara, A.C. Londoño et al. 1202 (COAH). P. paniculatum Engl. var. riedelianum (Engl.) Daly. Brasil: Amapá: Mazagão, M.J. Pires et al. 721, XI-1985, det. W. Milliken (INPA). Amazonas: Presidente Figueiredo, C.A. Cid Ferreira et al. 8254, IX1985 (INPA); Manaus, Rio Negro, G.T. Prance et al. 15899 X-1971 (INPA). Pará: Rio Acará, D. Daly et al. 827, XI-1980 (INPA); Tucuruí, J. Ramos 1039, XI-1983 (INPA); J. Ramos 1065, XI-1983 (INPA)*. P. pedicellatum Swart. Brasil: Amazonas: Manaus-Caracaraí, A.L. Mesquita, D. Coêlho 182 VIII-1981, det. A.L. Mesquita, D. Coêlho (HITAM)*. P. rubrum Cuatrec. Brasil: Pará, J.M. Pires 7109 , det. J. Cuatrecasas (IAN)*. P. sagotianum March. Brasil: Rondônia: Costa Márquez, M. Nee 34579, III-1987 (SP). Colômbia: Amazonas: San Juan de Arama, J.M. Idrobo, Schultes 1317 I-1951, det. J. Cuatrecasas conf. D. Daly (COL). Chocó: Riosucio, D. Cárdenas 2137, VI-1988 (JAUM). Meta: Sierra de La Macarena, Caño Ciervo, W.R. Philipson et al. 2108, I1950, det. J. Cuatrecasas, conf. D. Daly (COL)*. P spruceanum (Benth.) Engl. [= P. almecega March.). Brasil: Mato Grosso: Serra do Roncador, G. Eiten, L.T. Eiten 9177, X-1968 (SP). Minas Gerais: Ituiutaba, O. Handro 836, IX1946 (SP)*. São Paulo: Moji-Guaçú, J. Mattos 15062, X1967 (SP); Martinho Prado, W. Mantovani 1041, IX-1980 (SP); Faz. Campininha, J.R. Mattos, N.F. Mattos 8206, IX1960 (SP). P. subserratum (Engl.) Engl. Brasil: Amazonas: Novo Airão, R. Miller 183, VII-1989 (HITAM)*; R. Miller 290, VII-1989, det. W. Milliken (HITAM); Furo do Castanho, M. F. Silva et al. 1026, VII- 1972 (INPA). Pará: Altamira; S.A. Da M. Souza et al. 183, det. N.A Rosa (MG). Rondônia: Porto Velho, L.O.A. Teixeira et al. 937, VI-1982 (INPA). $P$. tenuifolium Engl. var. herbertii Cuatrec. Colômbia: Magdalena: Santa Marta, H.H. Smith 405, 1898-1901, det. J. Cuatrecasas (COL); H. H. Smith 1741 (Isótipo), 1898-1901, det. J. Cuatrecasas (COL)*. P. trifoliolatum Engl. Brasil Amazonas: Manaus, W. Rodrigues, D. Coêlho, 2618, X-1961 (INPA)*; Manaus-Itacoatiara, km 134, W. Rodrigues, D. Coêlho 7370, XII-1965, det. M.J. Pires (HITAM). P. unifoliolatum (Spruce) Engl. Brasil: Amazonas: Obras da U.H.T., F.F. Da Silva et al. 258, XI-1983 (MG). Mato Grosso: Serra do Cachimbo, O. Nascimento $492(\mathrm{MG})^{*}$; Serra do
Roncador, G. Eiten, L.T. Eiten 9202, X-1968, det. R.M. Harley (SP). P. vestitum (Cuatrec.) Daly [=Paraprotitum vestitum Cuatrec.]. Colômbia: Cauca: Río Micay, J. Cuatrecasas 14193 (Isótipo), II-1943, det. J. Cuatrecasas (VALLE). Valle: Río Naya, J. Cuatrecasas 14069, II-1943, det. J. Cuatrecasas (VALLE)*

Tetragastris altissima (Aubl.) Swart. Brasil: Maranhão: Br-316, D. Daly et al. 182, IX-1980 (INPA)*. Mato Grosso: Rio Apiaçá, W. Thomas et al. 4124, IX-1985 (INPA). Pará: Almeirim, M.J. Pires, N.T. Silva 1436, X-1986 (INPA); M.R. Santos 470, XII1978, det. M.R. Santos (HITAM). Venezuela: Bolívar: Río Grande, F.J. Breteler 3798, det. F.J. Breteler (MEDEL). T. panamensis (Engl.) Kuntze. Bolívia: Guayaramirín, J. C. Solomon 6400, IX-1981 (INPA). Brasil: Amapá: Oiapoque, R.L. Froés 26614, X-1950 (SP). Amazonas: Rio Negro-Camanaus, G.T. Prance et al. 16026, XI-1971 (INPA)*; Manaus-INPA, D. Coêlho, C.A. Cid Ferreira 155, VIII-1977 (INPA). Rondônia: Porto Velho, F. Dionízia et al. 160, VIII- 1987 (INPA). Equador: Napo: Río Napo, W. Palacios 3019, IX-1988, det. W. Palacios (JAUM).

Também foram estudados alguns materiais determinados como $P$. divaricatum, $P$. guianense, $P$. paniculatum e $P$. tenuifolium sem identificação infra-específica: $P$. divaricatum Engl. Brasil: Acre: Rio Purus, G.T. Prance et al. 2498, IX-1966 (INPA). Amazonas: Rio Trombetas, J. Revilla et al. 7041, VIII1982 (INPA); Rio Uatumã, C.A. Cid Ferreira et al. 349, VIII1979 (INPA); Tefé, C.A. Cid Ferreira, J. Lima 3303, 1982 (INPA); J.L. Amaral et al. 173, X-1982 (INPA). Rondônia: Porto Velho, C. D. Mota, L. Coêlho 83, IX-1975 (INPA). P. guianense (Aubl.) March. Colômbia: Vaupés: Río Kuduyarí, R.E. Schultes, I. Cabrera 14233, X-1951, det. J. Cuatrecasas (COL). P. paniculatum Engl. Brasil: Amazonas, Chagas s.n. (MG). Pará: Rio Mapuira, L.S. Coêlho et al. 148, XI-1985 (INPA). Colômbia: Antioquia: San Luis, Río Claro, A. Cogollo 1748, VI-1984 (HUA). P tenuifolium (Engl.) Engl. Brasil: Amapá, B.V. Rabelo, R. Souza 2936 (MG); Ramal do Camaipi-Mazagão, B.V. Rabelo et al. 3246, XI-1985, det. B.V. Rabelo (INPA). Amazonas: Manaus, G.T. Prance et al. 17541, IX- 1973 (INPA). Colômbia: Antioquia: Campamento, R. Callejas et al. 8289, IX- 1989 (HUA). Venezuela: Barinas: Río Barragán, A. Quintero 2206, XII-1977 (SP).

Os grãos de pólen foram preparados para estudos ao nível de microscopia óptica (Erdtman 1960) e de microscopia eletrônica de varredura (Aguilar-Sierra 1995). No material padrão foram obtidas medidas dos diâmetros polar e equatorial, em vista equatorial, e do diâmetro equatorial, em vista polar, de 25 grãos de pólen tomados ao acaso. Para as medidas dos materiais de comparação, das aberturas e da espessura da exina, foram utilizadas amostras de 10 grãos de pólen. Todas estas medidas receberam tratamento estatístico adequado ao tamanho da amostra. A variabilidade no número das aberturas é dada em porcentagem; foram considerados grãos de pólen raros, aqueles que não apareceram na amostra $(\mathrm{n}=100)$, tomada ao acaso, para a contagem da variação no número de aberturas, mas foram registrados na população, representada pelo total de lâminas examinadas. As fotomicrografias foram obtidas num fotomicroscópio Olympus Vanox, com câmara de exposição automática incorporada e as elétron-micrografias num MEV Zeiss DSM-940.

\section{Resultados}

A tabela 1 mostra as características morfopolínicas e as tabelas 2 e 3 os dados quantitativos das espécies 
Tabela 1. Caracterização morfológica dos grãos de pólen de espécies de Crepidospermum e Tetragastris.

\begin{tabular}{lccccc}
\hline Espécies & P/E & Forma & Endoabertura & Cólporos & Figuras \\
\hline C. cuneifolium & 1,21 & Subprolata & Elíptica & 3 & $1-3$ \\
C. goudotianum & 1,31 & Subprolata & Elíptica & 3 & $4-5$ \\
C. prancei & 1,50 & Prolata & Retangular & $(2)-3$ & $6-9$ \\
C. rhoifolium & 1,32 & Subprolata & Retangular* & $(2)-3$ & $(2)-3$ \\
T. altissima & 1,58 & Prolata & Retangular & $10-12$ \\
T. panamensis & 1,36 & Prolata & Retangular & $(2)-3$ & $13-14$ \\
\hline
\end{tabular}

* retangular, pseudo-sinclinorada

Tabela 2. Medidas, em $\mu \mathrm{m}$, dos diâmetros polar e equatorial dos grãos de pólen de espécies de Crepidospermum e Tetragastris, em vistas equatorial (VE) e polar (VP).

\begin{tabular}{|c|c|c|c|c|c|c|}
\hline \multirow{2}{*}{ Espécies } & \multicolumn{2}{|c|}{ Diâm. polar (VE) } & \multicolumn{2}{|c|}{ Diâm. equatorial (VE) } & \multicolumn{2}{|c|}{ Diâm. equatorial (VP) } \\
\hline & $\overline{\mathrm{x}} \pm \mathrm{s}_{\overline{\mathrm{x}}}$ & I.C. & $\overline{\mathrm{x}} \pm \mathrm{s}_{\overline{\mathrm{x}}}$ & I.C. & $\overline{\mathrm{x}} \pm \mathrm{s}_{\overline{\mathrm{x}}}$ & I.C. \\
\hline C. cuneifolium & $29,90 \pm 0,36$ & $29,17-30,64$ & $24,68 \pm 0,24$ & $24,18-25,17$ & $22,57 *$ & - \\
\hline C. goudotianum & $31,46 \pm 0,31$ & $30,82-32,11$ & $23,96 \pm 0,26$ & $23,43-24,50$ & $23,29 \pm 0,22$ & $22,83-23,74$ \\
\hline C. prancei & $33,04 \pm 0,27$ & $32,48-33,60$ & $22,07 \pm 0,25$ & $21,55-22,58$ & $21,27 \pm 0,20$ & $20,86-21,68$ \\
\hline C. rhoifolium & $36,15 \pm 0,41$ & $35,31-36,99$ & $27,43 \pm 0,32$ & $26,78-28,09$ & $23,11 *$ & - \\
\hline T. altissima & $27,06 \pm 0,20$ & $26,66-27,47$ & $17,11 \pm 0,12$ & $16,86-17,37$ & $17,32+0,12$ & $17,09-17,56$ \\
\hline T. panamensis & $25,87 \pm 0,24$ & $25,38-26,36$ & $19,05 \pm 0,15$ & $18,74-19,36$ & $19,10 \pm 0,19$ & $18,71-19,50$ \\
\hline
\end{tabular}

$* \mathrm{n}<5$

estudadas de Crepidospermum e Tetragastris que apresentam grãos de pólen médios; isopolares; subprolatos ou prolatos; âmbito triangular, goniotremados; (2)-3-colporados, colpos longos e estreitos, tenuimarginados; endoabertura lalongada, elíptica ou retangular; membrana do colpo granulada; exina psilada; nexina dividida em $\mathrm{n}_{1}, \mathrm{e}_{2}$, mais espessa do que a sexina; ao nível da endoabertura, a sexina separa-se consideravelmente da nexina que forma a costa ao redor da endoabertura. O exame ao MEV confirmou que em todas as espécies a exina é psilada.

Comentários - Em C. cuneifolium o colpo é inconspícuo quando observado em foco alto (figura 3 ) e em C. rhoifolium a endoabertura é grande, pseudosinclinorada, quando o grão de pólen está em vista equatorial, com uma das aberturas na posição central (figuras 10 e 11). Nos materiais padrão de C. prancei, T. altissima, T. panamensis, e nos materiais de comparação C. rhoifolium (Prance et al. 13752) e T. panamensis (Solomon 6400), os grãos de pólen 2-colporados são raros.

As medidas dos materiais de comparação de $C$. goudotianum e C. rhoifolium (tabela 4) mostram que, em muitos exemplares, a forma dos grãos de pólen não se mantém constante com relação ao material padrão; as médias aritméticas dos diâmetros polar e equatorial dos materiais de comparação situam-se,

Tabela 3. Média aritmética, em $\mu \mathrm{m}$, das medidas das aberturas e da exina dos grãos de pólen de espécies de Crepidospermum e Tetragastris $(\mathrm{n}=10)$.

\begin{tabular}{|c|c|c|c|c|c|c|c|c|}
\hline \multirow{2}{*}{ Espécies } & \multicolumn{2}{|c|}{ Colpo } & \multicolumn{3}{|c|}{ Endoabertura } & \multirow{2}{*}{ Exina } & \multirow{2}{*}{ Sexina } & \multirow{2}{*}{ Nexina } \\
\hline & Compr. & Larg. & Compr. & Larg. & Costa & & & \\
\hline C. cuneifolium & 17,68 & 2,40 & 6,46 & 10,29 & 1,37 & 1,83 & 0,90 & 0,94 \\
\hline C. goudotianum & 21,76 & 1,70 & 4,91 & 9,36 & 1,09 & 1,81 & 0,86 & 0,97 \\
\hline C. prancei & 21,75 & 1,49 & 6,35 & 10,03 & 1,32 & 1,96 & 0,85 & 1,17 \\
\hline C. rhoifolium & 21,03 & 1,34 & 7,62 & 11,60 & 1,56 & 1,63 & 0,67 & 0,96 \\
\hline T. altissima & 18,57 & 1,50 & 4,39 & 9,17 & 1,13 & 1,78 & 0,81 & 1,04 \\
\hline T. panamensis & 20,42 & 1,50 & 4,27 & 8,61 & 1,06 & 1,84 & 0,88 & 1,00 \\
\hline
\end{tabular}




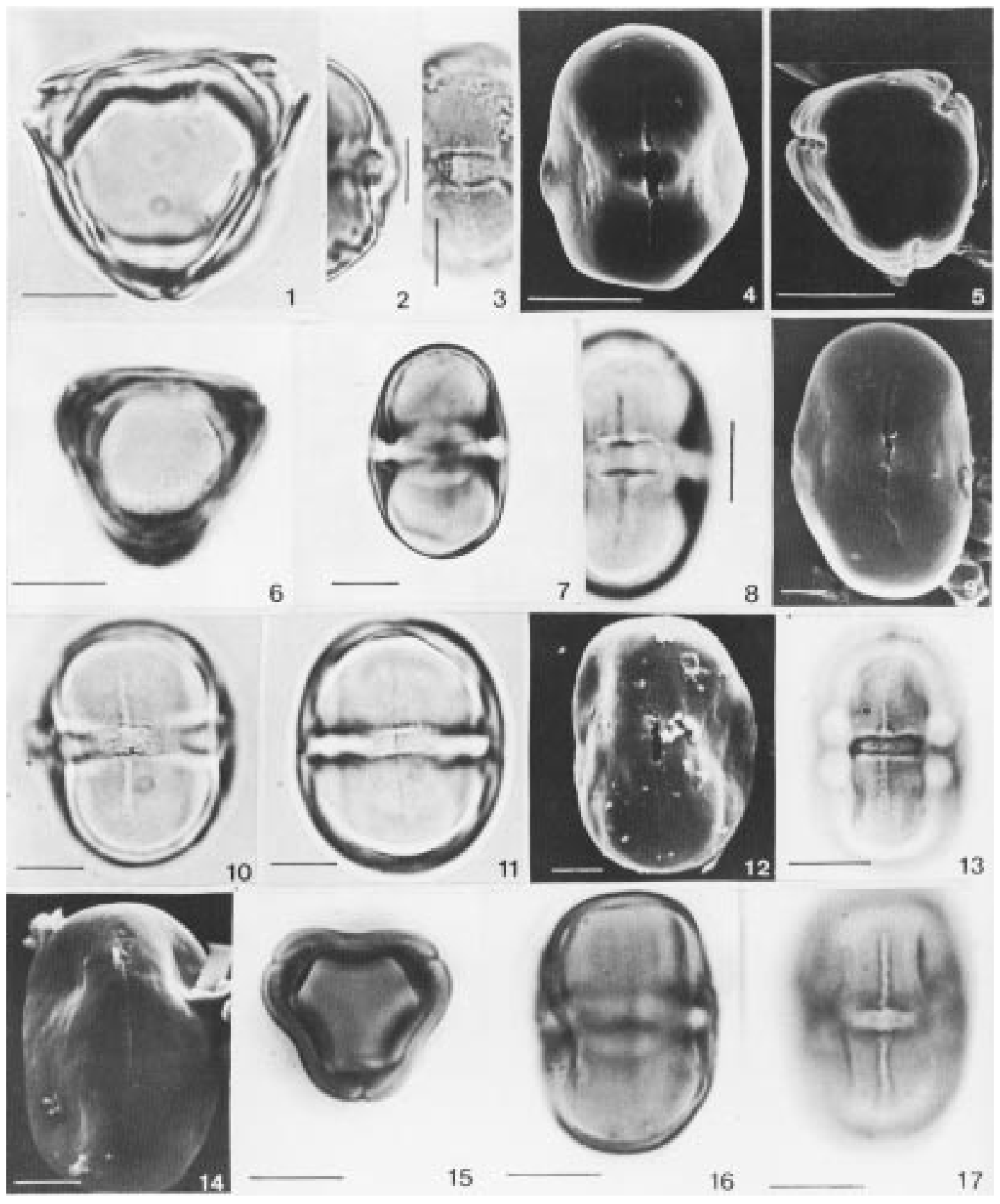

Figuras 1-17. Fotomicrografias e elétron-inicrografias dos grãos de pólen de espécies de Crepidospermum e Tetragastris. 1-3. C. cuneifolium. 1. Vista polar, contorno; 2-3. Detalhes da costa (2) e da endoabertura (3); 4-5. C. goudotianum. MEV (escalas $=10 \mu \mathrm{m})$ : vista equatorial, sexina psilada (4), vista polar, membrana do colpo granulada (5). 6-9. C. prancei. 6. Vista polar, contorno; 7. Vista equatorial, corte óptico; 8. Detalhe do cólporo. 9. MEV. Vista equatorial, sexina psilada (escala $=5 \mu \mathrm{m}) ; 10-12$. C. rhoifolium. 10-11. Vista equatorial em diferentes focos, grão de pólen pseudo-sinclinorado; 12. MEV: vista equatorial, sexina psilada, membrana do colpo granulada (escala $=5 \mu \mathrm{m}) ; 13-14$. T. altissima. 13. Detalhe do cólporo, membrana do colpo granulada; 14. MEV: vista equatorial, sexina psilada (escala $=6 \mu \mathrm{m}) ; 15-17$. T. panamensis. 15-16. Contorno em vista polar (15) e em vista equatorial (16); 17. Vista equatorial, cólporo. Escala das fotomicrografias $=10 \mu \mathrm{m}$. 
Tabela 4. Média aritmética das medidas dos grãos de pólen dos materiais de comparação de espécies de Protieae (n=10).

\begin{tabular}{|c|c|c|c|c|}
\hline \multirow{2}{*}{ Espécies } & \multicolumn{2}{|c|}{ Vista equatorial $(\mu \mathrm{m})$} & \multirow{2}{*}{$\begin{array}{l}\text { Vista polar }(\mu \mathrm{m}) \\
\text { Diâm. equatorial }\end{array}$} & \multirow{2}{*}{$\mathrm{P} / \mathrm{E}$} \\
\hline & Diâm. polar & Diâm. equatorial & & \\
\hline \multicolumn{5}{|l|}{ Crepidospermum goudotianum } \\
\hline (Cuatrecasas 7374) & 30,41 & 20,88 & - & $1,46^{\mathrm{b}}$ \\
\hline (Daly et al. 1320) & 30,55 & $24,11^{\mathrm{a}}$ & - & 1,27 \\
\hline (Daly et al. 1477) & 32,34 & $24,34^{\mathrm{a}}$ & - & 1,33 \\
\hline (Idrobo \& Jaramillo 2128) & 34,56 & 26,62 & - & 1,30 \\
\hline (Maciei et al. 718) & 32,92 & 25,11 & - & 1,31 \\
\hline (Thomas et al. 4042) & 32,16 & 22,56 & - & $1,43^{\mathrm{b}}$ \\
\hline \multicolumn{5}{|l|}{ Crepidospermum rhoifolium } \\
\hline (Cid Ferreira et al. 1837) & $35,87^{\mathrm{a}}$ & 26,40 & - & $1,36^{\mathrm{b}}$ \\
\hline (Cid Ferreira et ai. 2298) & 35,18 & $27,33^{\mathrm{a}}$ & - & 1,29 \\
\hline (Daly et al. 5980) & 33,05 & 22,82 & - & $1,45^{\mathrm{b}}$ \\
\hline (Duarte 7052) & 31,67 & 23,19 & - & $1,37^{\mathrm{b}}$ \\
\hline (Prance et al. 13752) & 32,96 & 25,87 & - & 1,27 \\
\hline (Rodrigues \& Lima 2345) & $36,22^{\mathrm{a}}$ & 26,33 & - & $1,38^{\mathrm{b}}$ \\
\hline (Silva et al. 596) & 33,30 & $27,13^{\mathrm{a}}$ & - & 1,23 \\
\hline \multicolumn{5}{|l|}{ Tetragastris altissima } \\
\hline (Breteler 3798) & 27,68 & 18,91 & 19,35 & 1,46 \\
\hline (Pires \& Silva 1436) & $27,11^{\mathrm{a}}$ & 19,73 & 19,24 & 1,37 \\
\hline (Santos 470) & 26,62 & 19,70 & 19,69 & 1,35 \\
\hline (Thomas et al. 4124) & 30,68 & 20,41 & 20,44 & 1,50 \\
\hline \multicolumn{5}{|l|}{ Tetragastris panamensis } \\
\hline (Coêlho \& Cid Ferreira 155) & 26,57 & $18,78^{\mathrm{a}}$ & 18,40 & 1,41 \\
\hline (Dionozia et al. 160) & 28,73 & 20,72 & 20,68 & 1,39 \\
\hline (Fróes 26614) & 29,96 & 22,67 & 24,02 & $1,32^{\mathrm{b}}$ \\
\hline (Palacios 3019) & 26,86 & 17,87 & 18,01 & 1,50 \\
\hline (Solomon 6400) & 29,50 & 19,74 & 19,95 & 1,49 \\
\hline
\end{tabular}

Comparando com o material padrão, os valores assinalados indicam: ${ }^{\text {a }}$ dentro do I.C.; ${ }^{\text {b forma diferente. }}$

freqüentemente, dentro da faixa de variação do material padrão. Na sua maioria, os dados obtidos em Tetragastris estão fora do intervalo de confiança e da faixa de variação do material padrão; a forma do pólen é mais constante, exceto para $T$. panamensis (Fróes 26614) cujos grãos de pólen são subprolatos $(\mathrm{P} / \mathrm{E}=1,32)$ valor este próximo do limite do intervalo de classe dos grãos de pólen prolatos.

A tabela 5 mostra as características morfopolínicas e as tabelas 6 e 7 os dados quantitativos das espécies estudadas de Protium que apresentam grãos de pólen pequenos a médios; isopolares; esféricos, prolato-esferoidais, subprolatos a prolatos; âmbito subtriangular a triangular ou subcircular, goniotremados; (2)-3-(4-5-6)-colporados, colpos longos (moderadamente longos em $P$. grandifolium e $P$. heptaphyllum, brevicolpos em P. macrophyllum), estreitos (exceto em $P$. altsonii, $P$. insigne e $P$. subserratum), tenuimarginados; endoaberturas providas de costa, lalongadas (constrictas ou não), elípticas ou retangulares, às vezes pseudo-sinclinoradas (quando muito largas, dando a falsa impres- são de unidas); normalmente o colpo está recoberto por uma membrana psilada, granulada ( $P$. altsonii, $P$. apiculatum, $P$. ferrugineum, $P$. nervosum e $P$. subserratum) ou microrreticulada ( $P$. carnosum, $P$. crassipetalum, $P$. divaricatum subsp. divaricatum e P. rubrum); em geral, a exina é delgada, o teto fino, a camada columelar estreita e a nexina, mais espessa do que a sexina, divide-se em $n_{1}$ e $n_{2}$; destaca-se a dificuldade para definir as camadas da exina, a fim de obter medidas precisas; sob microscopia óptica, exina psilada (82,2\% dos táxons), microrreticulada $(13,3 \%)$ ou com ornamentação indefinida $(4,5 \%)$.

As observações ao MEV confirmam muitas das descrições feitas, sob microscopia óptica, quanto à ornamentação da exina. A tabela 5 mostra que os grãos de pólen definidos, sob microscopia óptica, como psilados foram assim caracterizados em MEV, em $66,7 \%$ dos táxons. A melhor resolução deste equipamento permitiu verificar, em outros táxons, que a superfície era psilado-perfurada $(23,3 \%)$ ou estriada (10,0\%). No caso dos grãos de pólen psiladoperfurados as perfurações podem ser inconspícuas, 
Tabela 5. Caracterização morfológica dos grãos de pólen de espécies de Protium $($ Tam = tamanho; $\mathrm{M}=$ médio; $\mathrm{P}=$ pequeno; ES = esférica; $\mathrm{PE}=$ prolata-esferoidal $; \mathrm{PR}=$ prolata; $\mathrm{SP}=$ subprolata $; \mathrm{PT}=$ pticotremado; $\mathrm{SC}=$ subcircular; $\mathrm{ST}=$ subtriangular; $\mathrm{T}=$ triangular; Endo = endoabertura; $\mathrm{E}=$ elíptica $; \mathrm{EC}=$ elíptica, constricta no centro; $\mathrm{R}=$ retangular; $\mathrm{RC}=$ retangular, constricta no centro; Rps = retangular, pseudo-sinclinorada; $\mathrm{MO}=$ microscopia óptica; $\mathrm{MEV}=$ microscopia eletrônica de varredura: Estr = estriada; $\mathrm{Micro}=$ microrreticulada; Orna = ornamentação indefinida; Psil = psilada; Psil-p = psilado-perfurada).

\begin{tabular}{|c|c|c|c|c|c|c|c|c|c|}
\hline \multirow{2}{*}{ Espécies } & \multirow{2}{*}{ Tam } & \multirow{2}{*}{$\mathrm{P} / \mathrm{E}$} & \multirow{2}{*}{ Forma } & \multirow{2}{*}{ Âmbito } & \multirow{2}{*}{ Cólporo } & \multirow{2}{*}{ Endo } & \multicolumn{2}{|c|}{ Exina } & \multirow{2}{*}{ Figuras } \\
\hline & & & & & & & MO & MEV & \\
\hline P. altsonii & M & 1,25 & SP & $\mathrm{T}$ & $3-(4-5-6)$ & $\mathrm{E}$ & Psil & Psil-p & $18-22$ \\
\hline P. amplum & M & 1,12 & $\mathrm{PE}$ & $\mathrm{SC}$ & (2)-3 & $\mathrm{E}$ & Psil & Psil-p & $23-25$ \\
\hline P. apiculatum & M & 1,48 & PR & $\mathrm{SC}$ & 3 & $\mathrm{E}$ & Orna & Estr & $26-29$ \\
\hline P. aracouchini & $\mathrm{m}$ & 1,33 & PR & $\mathrm{T}$ & (2)-3-(4-5) & $\mathrm{E}$ & Psil & Psil & $30-36$ \\
\hline P. brasiliense & M & 1,13 & $\mathrm{PE}$ & $\mathrm{SC}$ & 3 & $\mathrm{E}$ & Psil & Psil & $37-40$ \\
\hline P. buenaventurense & M & 1,30 & SP & $\mathrm{T}$ & 3 & $\mathrm{E}$ & Psil & Psil & $41-43$ \\
\hline P. calanense & M & 1,74 & PR & $\mathrm{SC}$ & 3 & $\mathrm{R}$ & Psil & Psil & $44-46$ \\
\hline P carnosum & $\mathrm{P}$ & 1,00 & ES & $\mathrm{SC}$ & 3 & $\mathrm{E}$ & Micro & Micro & $47-56$ \\
\hline P. cranipyrenum & M & 1,35 & PR & $\mathrm{T}$ & $(2)-3$ & $\mathrm{EC}$ & Psil & Psil-p & $57-59$ \\
\hline$P$ crassipetalum & $\mathrm{P}$ & 1,10 & $\mathrm{PE}$ & ST & 3 & $\mathrm{E}$ & Micro & Micro & $60-66$ \\
\hline P. crenatum & M & 1,39 & PR & $\mathrm{T}$ & 3 & $\mathrm{E}$ & Psil & Psil & $67-71$ \\
\hline P. dawsonii & M & 1,17 & SP & $\mathrm{T}$ & $(2)-3$ & $\mathrm{E}$ & Psil & Psil & $72-75$ \\
\hline P. decandrum & M & 1,34 & PR & $\mathrm{T}$ & 3 & $\mathrm{E}$ & Psil & - & $76-78$ \\
\hline P.divaricatum subsp. divaricatum & M & 1,32 & SP & - & 3 & $\mathrm{RC}$ & Micro & Micro & $79-80$ \\
\hline P. divaricatum subsp. fumarium & M & 1,81 & PR & - & 3 & $\mathrm{R}$ & Psil & - & $81-82$ \\
\hline P. elegans & P-M & 1,40 & PR & $\mathrm{T}$ & $(2)-3-(4)$ & $\mathrm{E}$ & Psil & Psil & $83-88$ \\
\hline P. ferrugineum & M & 1,50 & PR & $\mathrm{SC}$ & (2) -3 & $\mathrm{E}$ & Psil & Psil-p & $89-92$ \\
\hline P. fimbriatum & $\mathrm{P}$ & 1,67 & PR & - & 3 & $\mathrm{E}$ & Psil & Estr & $93-95$ \\
\hline P.cf. gallosuin & $\mathrm{P}$ & 1,37 & PR & $\mathrm{SC}$ & 3 & $\mathrm{E}$ & Psil & Estr & $96-99$ \\
\hline P. giganteum & M & 1,30 & SP & $\mathrm{T}$ & $3-(4)$ & $\mathrm{R}$ & Psil & Psil & $100-103$ \\
\hline P. grandifolium & P-M & 1,22 & SP & $\mathrm{T}$ & $(2)-3-(4)$ & $\mathrm{E}$ & Psil & Psil & 104-106 \\
\hline P. guianense subsp. pilosissimum & $\mathrm{P}$ & 1,27 & SP & - & 3 & $\mathrm{E}$ & Psil & - & $107-108$ \\
\hline P. hebetatum & P-M & 1,31 & SP & $\mathrm{T}$ & $(2)-3-(4)$ & $\mathrm{R}$ & Psil & Psil & $109-112$ \\
\hline P. heptaphyllum & M & 1,19 & SP & $\mathrm{T}$ & (2) -3 & $\mathrm{E}$ & Psil & - & $113-115$ \\
\hline P. insigne & M & 1,86 & PR & - & 3 & $\mathrm{E}$ & Psil & - & $116-117$ \\
\hline P. cf. lepiostachyum & M & 1,56 & PR & - & $3-(4)$ & Rps & Psil & - & 118 \\
\hline P. llanorum & M & 1,24 & SP & $\mathrm{T}$ & $(2)-3$ & $\mathrm{E}$ & Psil & Psil & $119-122$ \\
\hline P. macrophyllum & M & 1,26 & SP & $\mathrm{T}$ & $(2)-3-(4)$ & $\mathrm{E}$ & Psil & Psil & $123-125$ \\
\hline P. minutiflorum & $\mathrm{P}$ & 1,37 & PR & $\mathrm{SC}$ & (2) -3 & $\mathrm{E}$ & Orna & Estr & $126-128$ \\
\hline P. neglectum & M & 1,35 & PR & $\mathrm{SC}$ & 3 & $\mathrm{E}$ & Micro & Psil-p & $129-132$ \\
\hline P. nervosum & M & 1,23 & SP & $\mathrm{T}$ & $3-(4)$ & $\mathrm{R}$ & Psil & Psil-p & $133-136$ \\
\hline P. nitidifolium & $\mathrm{P}$ & 1,35 & PR & $\mathrm{SC}$ & $3-(4)$ & $\mathrm{E}$ & Psil & Estr & $137-140$ \\
\hline P. opacum subsp. rabelianum & M & 1,40 & PR & $\mathrm{T}$ & $(2)-3$ & $\mathrm{E}$ & Psil & Psil & $141-143$ \\
\hline P. ovatum & M & 1,19 & SP & $\mathrm{T}$ & (2)-3 & $\mathrm{E}$ & Psil & Psil & 144-149 \\
\hline P. paniculatum var. paniculatum & $\mathrm{M}$ & 1,30 & SP & $\mathrm{T}$ & $3-(4)$ & $\mathrm{E}$ & Psil & Psil-p & $150-154$ \\
\hline P. paniculatum var. riedelianum & M & 1,40 & PR & $\mathrm{T}$ & $3-(4)$ & $\mathrm{E}$ & Psil & Psil & $155-159$ \\
\hline P. pedicellatum & M & 1,29 & SP & - & 3 & $\mathrm{R}$ & Psil & - & 160 \\
\hline P. rubrum & $\mathrm{P}$ & 1,03 & PE & $\mathrm{SC}$ & 3 & $\mathrm{E}$ & Micro & - & $161-162$ \\
\hline P. sagotianum & M & 1,14 & SP & ST & (2)-3 & $\mathrm{E}$ & Micro & - & $163-167$ \\
\hline P. spruceanum & M & 1,31 & SP & $\mathrm{T}$ & $(2)-3-(4)$ & $\mathrm{E}$ & Psil & Psil & $168-171$ \\
\hline P. subserratum & M & 1,72 & PR & SC-PT & 3 & $\mathrm{E}$ & Psil & Psil & $172-175$ \\
\hline P. tenuifolium var. herbertii & M & 1,33 & PR & $\mathrm{SC}$ & $(2)-3$ & $\mathrm{E}$ & Psil & Psil-p & $176-179$ \\
\hline P. trifoliolatum & M & 1,45 & PR & $\mathrm{T}$ & (2)-3 & Rps & Psil & Psil & $180-182$ \\
\hline P. unifoliolatum & M & 1,40 & PR & $\mathrm{T}$ & $(2)-3-(4)$ & $\mathrm{R}$ & Psil & Psil & $183-186$ \\
\hline P. vestitum & M & 1,45 & PR & $\mathrm{T}$ & $3-(4)$ & $\mathrm{R}$ & Psil & Psil & $187-188$ \\
\hline
\end{tabular}

esparsas por toda a superfície do pólen (P. altsonii, figura 21); faltam na área que circunda o cólporo apresentando o teto ondulado, com perfurações conspícuas e próximas ( $P$. amplum, figura 25; $P$. cranipyrenum, figura 59 e $P$. nervosum, figura 136), ou, o teto psilado, com perfuracões maiores no apocolpo de alguns grãos de pólen ( $P$. ferrugineum, figuras 91 e 92); em P. tenuifolium var. herbertii as perfurações são mais conspícuas nos pólos (figuras 178 e 179), enquanto em $P$. paniculatum var. paniculattim ocorrem apenas na região polar (figura 154). 

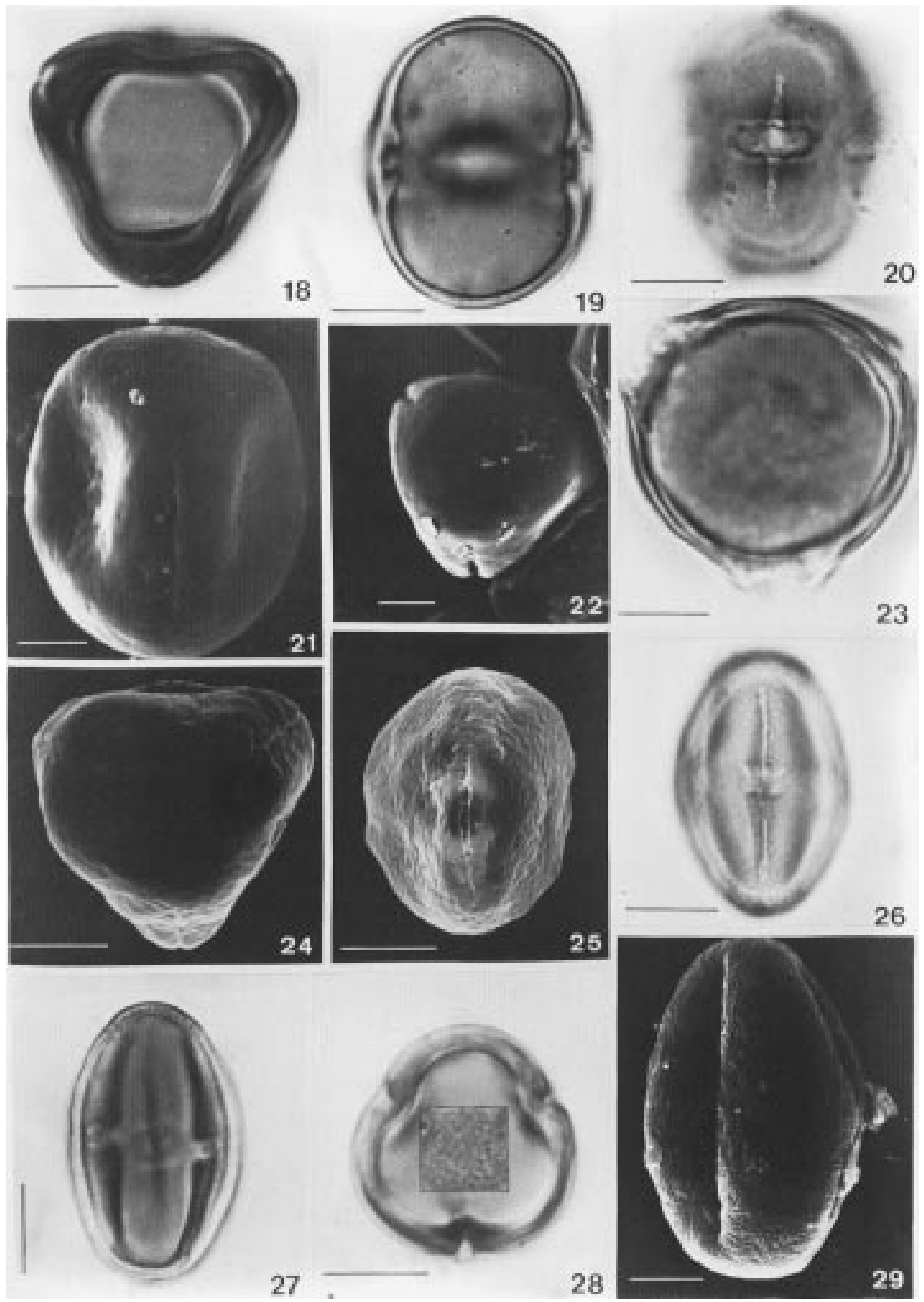

Figuras 18-29. Fotomicrografias e elétron-micrografias dos grãos de pólen de espécies de Protium. 18-22. P altsonii. 18. Vista polar, contorno; 19-20. Vista equatorial, corte óptico (19), detalhe da abertura, endoabertura elíptica (20); 21-22. MEV (escalas = $5 \mu \mathrm{m})$ : vista equatorial, sexina psilado-perfurada (21), vista polar (22). 23-25. P. amplum. 23. Vista polar, contorno; 24-25. MEV (escalas $=10 \mu \mathrm{m})$ : vista polar (24), vista equatorial, sexina psilado-perfurada, abertura circundada por área psilada (25). 26-29. P apiculatum. 26-27. Vista equatorial, cólporo (26), contorno (27); 28. Vista polar, contorno, detalhe da ornamentação no centro do grão de pólen; 29. MEV: vista equatorial, sexina estriada (escala $=5 \mu \mathrm{m}$ ). Escala das fotomicrografias $=10 \mu \mathrm{m}$. 
Tabela 6. Medidas, em $\mu \mathrm{m}$, dos diâmetros polar e equatorial dos grãos de pólen de espécies de Protium $(\mathrm{VE}=$ vista equatorial; $\mathrm{VP}=$ vista polar; $\mathrm{n}=25 ; * \mathrm{n}<20$ ).

\begin{tabular}{|c|c|c|c|c|c|c|}
\hline \multirow{2}{*}{ Espécies } & \multicolumn{2}{|c|}{ Diâm. polar (VE) } & \multicolumn{2}{|c|}{ Diâm. equatorial (VE) } & \multicolumn{2}{|c|}{ Diâm. equatorial (VP) } \\
\hline & $\overline{\mathrm{x}} \pm \mathrm{s}_{\overline{\mathrm{x}}}$ & I.C. & $\mathrm{x} \pm \mathrm{s}_{\overline{\mathrm{x}}}$ & I.C. & $\overline{\mathrm{x}} \pm \mathrm{s}_{\overline{\mathrm{x}}}$ & I.C. \\
\hline P. altsonii & $28,11 \pm 0,28$ & $27,82-28,38$ & $22,53 \pm 0,24$ & $22,04-23,02$ & $21,74 \pm 0,24$ & $21,25-22,23$ \\
\hline P. amplum & $29,05 \pm 0,34$ & $28,35-29,76$ & $25,84 \pm 0,54$ & $24,73-26,96$ & $25,46 \pm 0,34$ & $24,76-26,15$ \\
\hline P. apiculatum & $26,12 \pm 0,23$ & $25,64-26,59$ & $17,60 \pm 0,21$ & $17,18-18,03$ & $17,99 *$ & - \\
\hline P. aracouchini & $25,94 \pm 0,29$ & $25,35-26,53$ & $19,49 \pm 0,19$ & $19,11-19,87$ & $19,08 \pm 0,22$ & $18,62-19,53$ \\
\hline P. brasiliense & $28,42 \pm 0,28$ & $27,84-29,02$ & $25,13 \pm 0,26$ & $24,59-25,67$ & $24,81 \pm 0,23$ & $24,34-25,28$ \\
\hline P. buenaventurense & $29,55 \pm 0,26$ & $29,01-30,09$ & $22,73 \pm 0,27$ & $22,16-23,29$ & - & - \\
\hline P. calanense & $28,80 \pm 0,30$ & $28,18-29,42$ & $16,55 \pm 0,16$ & $16,22-16,87$ & $15,50 *$ & - \\
\hline P. carnosum & $17,75 \pm 0,25$ & $17,24-18,25$ & $17,81 \pm 0,22$ & $17,36-18,25$ & $17,58 \pm 0,18$ & $17,20-17,96$ \\
\hline P. cranipyrenum & $33,20 \pm 0,27$ & $32,64-33,77$ & $24,66 \pm 0,35$ & $23,94-25,37$ & - & - \\
\hline P. crassipetalum & $20,90 \pm 0,18$ & $20,52-21,28$ & $18,99 \pm 0,15$ & $18,69-19,30$ & $19,76 \pm 0,15$ & $19,44-20,08$ \\
\hline P. crenatum & $26,41 \pm 0,21$ & $25,99-26,84$ & $18,98 \pm 0,15$ & $18,68-19,29$ & $18,93 \pm 0,17$ & $18,59-19,28$ \\
\hline P. dawsonii & $27,41 \pm 0,24$ & $26,92-27,90$ & $23,35 \pm 0,22$ & $22,91-23,80$ & $22,13 \pm 0,22$ & $21,67-22,59$ \\
\hline P. decandrum & $26,04 \pm 0,27$ & $25,48-26,60$ & $19,42 \pm 0,24$ & $18,93-19,90$ & $20,39 \pm 0,18$ & $20,01-20,77$ \\
\hline \multicolumn{7}{|l|}{ P. divaricatum subsp. } \\
\hline divaricatum & $29,31 \pm 0,25$ & $28,78-29,83$ & $22,26 \pm 0,22$ & $21,80-22,72$ & - & - \\
\hline \multicolumn{7}{|l|}{ P. divaricatum subsp. } \\
\hline fumarium & $31,68 \pm 0,53$ & $30,58-32,77$ & $17,55 \pm 0,25$ & $17,03-18,07$ & - & - \\
\hline P. elegans & $25,40 \pm 0,31$ & $24,75-26,05$ & $18,15 \pm 0,14$ & $17,86-18,44$ & $18,28 \pm 0,22$ & $17,82-18,73$ \\
\hline P. ferrugineum & $34,01 \pm 0,33$ & $33,33-34,69$ & $22,73 \pm 0,24$ & $22,24-23,22$ & $26,58^{*}$ & - \\
\hline P. fimbriatum & $24,07 \pm 0,22$ & $23,61-24,54$ & $14,44 \pm 0,25$ & $13,92-14,96$ & - & - \\
\hline P. cf. gallosum & $19,28 \pm 0,24$ & $18,78-19,78$ & $14,06 \pm 0,14$ & $13,77-14,36$ & $14,30 *$ & - \\
\hline P. giganteum & $27,95 \pm 0,19$ & $27,56-28,35$ & $21,48 \pm 0,13$ & $21,22-21,75$ & $20,90 \pm 0,17$ & $20,55-21,24$ \\
\hline P. grandifolium & $25,13 \pm 0,23$ & $24,64-25,61$ & $20,58 \pm 0,22$ & $20,12-21,04$ & $19,60 \pm 0,16$ & $19,27-19,92$ \\
\hline \multicolumn{7}{|l|}{ P. guianense subsp. } \\
\hline pilosissimum & $23,29 \pm 0,23$ & $22,81-23,77$ & $18,37 \pm 0,14$ & $18,09-18,66$ & - & - \\
\hline P. hebetatum & $25,20 \pm 0,21$ & $24,77-25,64$ & $19,22 \pm 0,24$ & $18,73-19,70$ & $18,37 *$ & - \\
\hline P. heptaphyllum & $29,56 \pm 0,30$ & $28,95-30,17$ & $24,95 \pm 0,28$ & $24,37-25,54$ & $24,30 \pm 0,34$ & $23,59-25,01$ \\
\hline P. insigne & $31,72 \pm 0,48$ & $30,74-32,70$ & $17,10 \pm 0,21$ & $16,66-17,54$ & - & - \\
\hline P. cf. leptostachyum & $25,68 \pm 0,20$ & $25,26-26,11$ & $16,49 \pm 0,12$ & $16,26-16,73$ & - & - \\
\hline P. llanorum & $26,32 \pm 0,28$ & $25,74-26,90$ & $21,25 \pm 0,19$ & $20,87-21,64$ & 20,68 v 0,13 & $20,42-20,95$ \\
\hline P. macrophyllum & $29,56 \pm 0,22$ & $29,10-30,01$ & $23,38 \pm 0,27$ & $22,82-23,93$ & $23,97 *$ & - \\
\hline P. minutiflorum & $21,10 \pm 0,15$ & $20,79-21,42$ & $15,45 \pm 0,17$ & $15,11-15,80$ & $15,23 \pm 0,15$ & $14,92-15,54$ \\
\hline P. neglectum & $35,33 \pm 0,23$ & $34,86-35,80$ & $26,09 \pm 0,23$ & $25,62-26,56$ & $26,99 *$ & - \\
\hline P. nervosum & $28,75 \pm 0,22$ & $28,30-29,20$ & $23,41 \pm 0,20$ & $23,00-23,82$ & $22,28 \pm 0,26$ & $21,75-22,82$ \\
\hline P. nitidifolium & $24,05 \pm 0,27$ & $23,49-24,60$ & $17,77 \pm 0,19$ & $17,38-18,16$ & $19,01 \pm 0,30$ & $18,39-19,64$ \\
\hline \multicolumn{7}{|l|}{ P. opacum subsp. } \\
\hline rabelianum & $30,13 \pm 0,20$ & $29,71-30,54$ & $21,52 \pm 0,18$ & $21,15-21,90$ & $21,34 *$ & - \\
\hline P. ovatum & $28,51 \pm 0,21$ & $28,08-28,94$ & $23,88 \pm 0,19$ & $23,48-24,28$ & $23,15 \pm 0,25$ & $22,64-23,66$ \\
\hline \multicolumn{7}{|l|}{ P. paniculatum var. } \\
\hline paniculatum & $26,23 \pm 0,21$ & $25,79-26,66$ & $20,21 \pm 0,17$ & $19,86-20,55$ & $20,05 \pm 0,17$ & $19,70-20,40$ \\
\hline \multicolumn{7}{|l|}{ P. paniculatum var. } \\
\hline riedelianum & $27,17 \pm 0,30$ & $26,55-27,78$ & $19,36 \pm 0,17$ & $19,02-19,71$ & $20,00 *$ & - \\
\hline P. pedicellatum & $25,48 \pm 0,22$ & $25,03-25,93$ & $19,71 \pm 0,18$ & $19,33-20,08$ & - & - \\
\hline P. rubrum & $18,79^{*}$ & - & $18,22^{*}$ & - & - & - \\
\hline P. sagotianum & $27,97 \pm 0,20$ & $27,56-28,38$ & $24,64 \pm 0,22$ & $24,18-25,10$ & $25,40 \pm 0,29$ & $24,80-26,01$ \\
\hline P. spruceanum & $28,92 \pm 0,21$ & $28,49-29,35$ & $22,16 \pm 0,21$ & $21,73-22,59$ & $21,38 \pm 0,18$ & $21,02-21,74$ \\
\hline P. subserratum & $38,38 \pm 0,38$ & $37,60-39,17$ & $22,28 \pm 0,26$ & $21,75-22,80$ & $22,03 *$ & - \\
\hline \multicolumn{7}{|l|}{ P. tenuifolium var. } \\
\hline herbertii & $33,58 \pm 0,28$ & $33,00-34,16$ & $25,20 \pm 0,30$ & $24,57-25,82$ & $25,30 *$ & - \\
\hline P. trifoliolatum & $25,94 \pm 0,28$ & $25,36-26,52$ & $17,91 \pm 0,16$ & $17,57-18,24$ & $17,17 *$ & - \\
\hline P. unifoliolatum & $27,35 \pm 0,26$ & $26,82-27,89$ & $19,53 \pm 0,13$ & $19,26-19,80$ & $19,57 \pm 0,16$ & $19,23-19,90$ \\
\hline P. vestitum & $32,01 \pm 0,29$ & $31,41-32,61$ & $22,08 \pm 0,23$ & $21,61-22,54$ & $22,18 \pm 0,19$ & $21,79-22,58$ \\
\hline
\end{tabular}




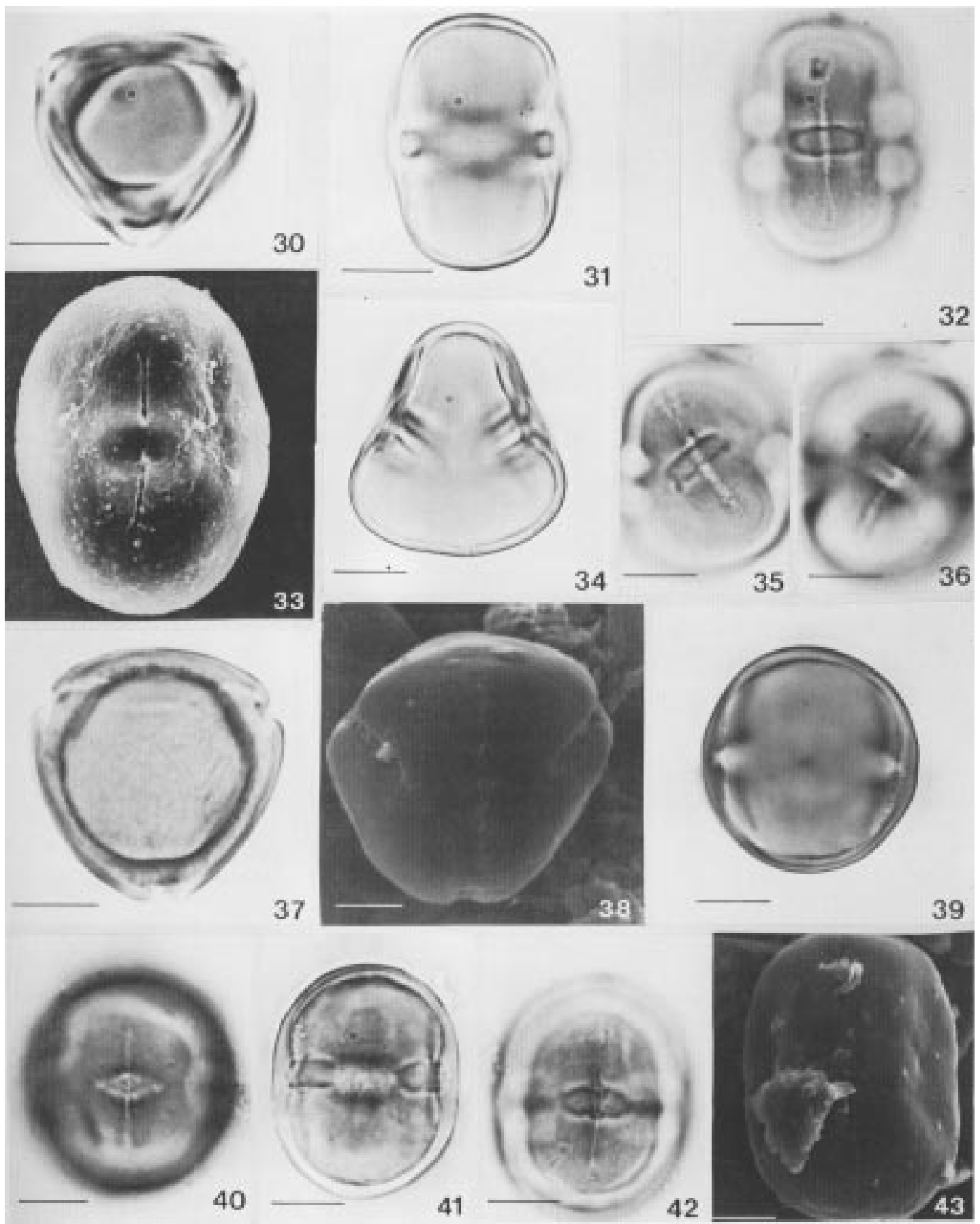

Figuras 30-43. Fotomicrografias e elétron-micrografias dos grãos de pólen de espécies de Protium. 30-36. P. aracouchini. 30-31. Contorno em vista polar (30) e em vista equatorial (31); 32. Vista equatorial, cólporo, endoabertura elíptica; 33. MEV: vista equatorial, sexina psilada $($ escala $=12 \mu \mathrm{m}) ; 34$. Vista equatorial, grão de pólen 4-colporado; 35-36. Vista equatorial, grão de pólen 4-loxocolporado, em diferentes focos; 37-40. P. brasiliense. 37. Vista polar, contorno; 38. MEV: vista polar, sexina psilada (escala $=5 \mu \mathrm{m})$; 39-40. Vista equatorial, corte óptico (39), cólporo, endoabertura elíptica (40); 41-43. P. buenaventurense. 41-42. Vista equatorial, corte óptico (41), cólporo, endoabertura elíptica (42); 43. MEV: vista equatorial, sexina psilada(escala $=5 \mu \mathrm{m}$ ). Escala das fotomicrografias $=10 \mu \mathrm{m}$. 


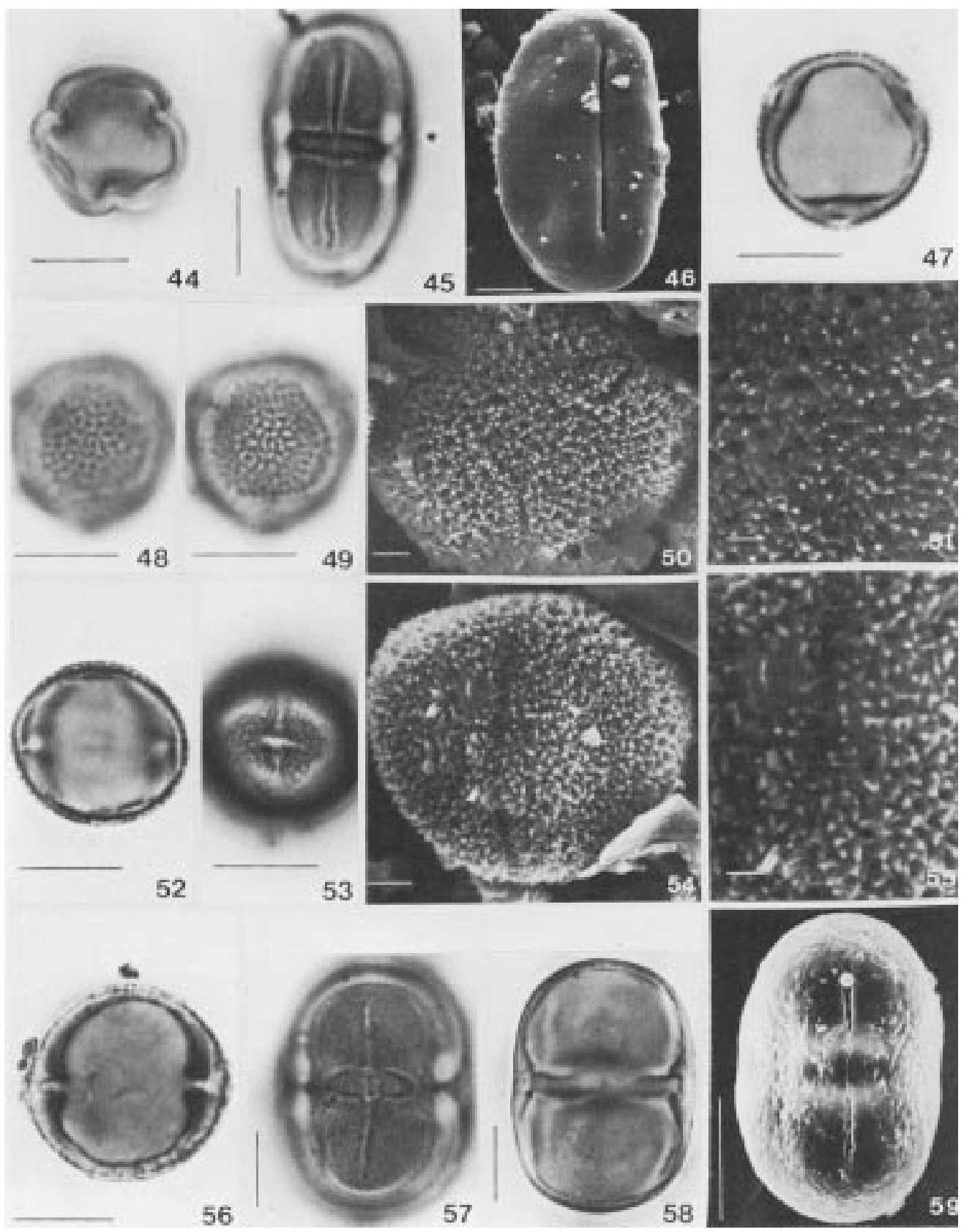

Figuras 44-59. Fotomicrografias e elétron-micrografias dos grãos de pólen de espécies de Protium. 44-46. P. calanense. 44. Vista polar, contorno; 45 . Vista equatorial, detalhe da abertura; 46. MEV: vista equatorial, sexina psilada (escala $=5 \mu \mathrm{m}$ ). 47-56. P. carnosum. 47 Vista polar, contorno; 48-49. Análise de L.O. mostrando a ornamentação microrreticulada; 50-51. MEV. 50. Vista polar (escala = 2 $\mu \mathrm{m})$; 51. Detalhe da ornamentação da exina na região polar (escala $1 \mu \mathrm{m}$ ); 52-53. Vista equatorial, corte óptico (52), detalhe do cólporo (53); 54-55. MEV. 54. Vista equatorial, abertura (escala $2 \mu \mathrm{m}$ ); 55. Detalhe da ornamentação da exina na região equatorial (escala $=1$ $\mu \mathrm{m})$; 56. Vista equatorial, grão de pólen 2-colporado. 57-59. P. cranipyrenum. 57-58.Vista equatorial, cólporo, endoabertura elíptica, constricta no centro (57), corte óptico (58), 59. MEV: vista equatorial abertura circundada por área psilada, sexina psilado-perfurada, entre as perfurações o teto é ondulado (escala $=10 \mu \mathrm{m}$ ). Escala das fotomicrografias $=10 \mu \mathrm{m}$. 


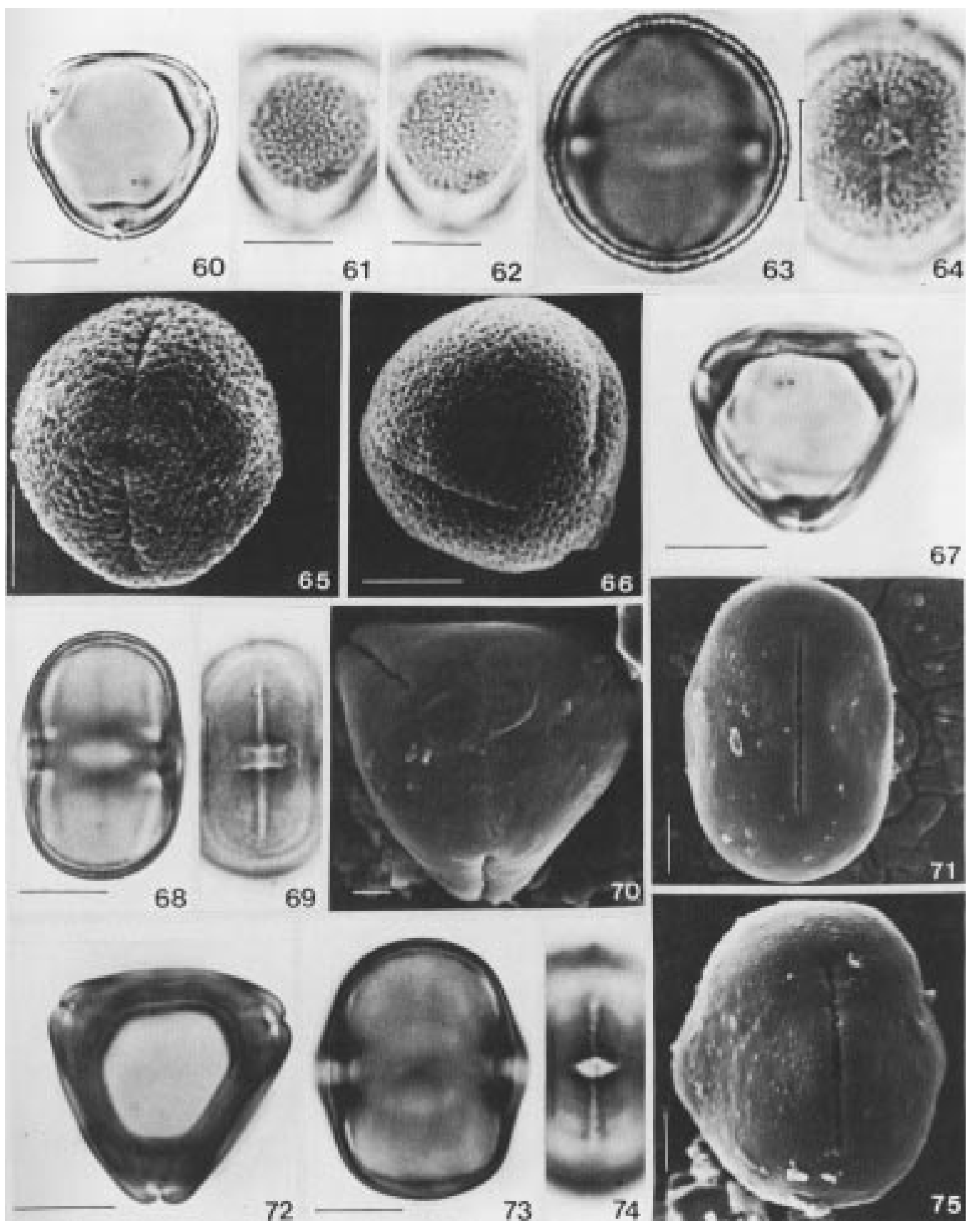

Figuras 60-75. Fotomicrografias e elétron-micrografias dos grãos de pólen de espécies de Protium. 60-66. P. crassipetalum. 60. Vista polar, contorno; 61-62. Análise de L.O. mostrando a ornamentação microrreticulada; 63-64. Vista equatorial, corte óptico (63), colporo, endoabertura elíptica (64); 65-66. MEV (escalas $=10 \mu \mathrm{m}$ ): vista equatorial, abertura (65), grão de pólen inclinado mostrando o mesocolpo e a região polar (66). 67-71. P. crenatum. 67. Vista polar, contorno; 68-69. Vista equatorial, corte óptico (68), detalhe do cólporo, endoabertura elíptica (69); 70-71. MEV. 70. Vista polar, sexina psilada (escala $=2 \mu \mathrm{m}) ; 71$. Vista equatorial, abertura $(\mathrm{escala}=5 \mu \mathrm{m})$. 72-75. P. dawsonii. 72. Vista polar, contorno; 73-74. Vista equatorial, corte óptico (73), detalhe da abertura, endoabertura elíptica (74); 75. MEV: vista equatorial, sexina psilada $($ escala $=5 \mu \mathrm{m})$. Escala das fotomicrografias $=10 \mu \mathrm{m}$. 
Os grãos de pólen estriados ao MEV, psilados ou com ornamentação indefinida sob microscopia óptica, apresentam estrias curtas, imbricadas em $P$. apiculatum (figuras 28 e 29), $P$. fimbriatum (figura 95), P. cf. gallosum (figuras 98 e 99) e P. nitidifolium (figura 140), ou longas, mais ou menos paralelas no mesocolpo em P. minutiflorum (figuras 126 e 128). Tais estrias são pouco proeminentes o que dificulta sua definição na resolução do microscópio óptico.
Nos grãos de pólen microrreticulados sob microscópio óptico, verificou-se ao MEV, a presença de muros ondulados em $P$. divaricatum subsp. divaricatum (figura 80) e de espículos sobre os muros do microrretículo em $P$. carnosum (figuras 50, 51,54 e 55) e $P$. crassipetalum (figuras 65 e 66). Em P. carnosum os lúmens (1) e os muros (m) do microrretículo são maiores na região polar (1. ca. $0,99 \mu \mathrm{m}$; m. ca. $0,91 \mu \mathrm{m}$ ) do que na equatorial (1. ca. $0,87 \mu \mathrm{m}$;

Tabela 7. Média aritmética, em $\mu \mathrm{m}$, das medidas das aberturas e da exina dos grãos de pólen de espécies de Protium $(\mathrm{n}=10)$.

\begin{tabular}{|c|c|c|c|c|c|c|c|c|}
\hline \multirow{2}{*}{ Espécies } & \multicolumn{2}{|c|}{ Colpo } & \multicolumn{3}{|c|}{ Endoabertura } & \multirow{2}{*}{ Exina } & \multirow{2}{*}{ Sexina } & \multirow{2}{*}{ Nexina } \\
\hline & Compr. & Larg. & Compr. & Larg. & Costa & & & \\
\hline P. altsonii & 17,77 & 2,04 & 5,97 & 11,11 & 1,29 & 1,81 & 0,86 & 0,98 \\
\hline P. amplum & 16,10 & 1,45 & 6,45 & 7,70 & 1,22 & 1,92 & 1,02 & 0,93 \\
\hline P. apiculatum & 20,83 & 1,53 & 3,85 & 7,47 & 1,14 & 1,98 & 0,98 & 1,04 \\
\hline P. aracouchini & 16,24 & 1,41 & 4,91 & 9,04 & 1,13 & 1,68 & 0,75 & 0,96 \\
\hline P. brasiliense & 17,84 & 1,55 & 5,40 & 10,09 & 1,15 & 2,20 & 0,96 & 1,24 \\
\hline P. buenaventurense & 18,96 & 1,16 & 5,47 & 10,04 & 1,08 & 2,03 & 0,94 & 1,14 \\
\hline P. calanense & 22,90 & 1,76 & 4,40 & 10,86 & 1,14 & 1,90 & 0,94 & 0,98 \\
\hline P. carnosum & 10,47 & 1,29 & 3,28 & 5,54 & 1,29 & 2,07 & 0,88 & 1,23 \\
\hline P. cranipyrenum & 23,57 & 1,27 & 5,86 & 11,96 & 1,22 & 1,98 & 0,93 & 1,06 \\
\hline P. crassipetalum & 17,99 & 1,08 & 4,09 & 6,58 & 1,20 & 2,13 & 0,95 & 1,23 \\
\hline P. crenatum & 19,24 & 1,77 & 5,27 & 8,86 & 1,35 & 1,88 & 0,87 & 1,06 \\
\hline P. dawsonii & 17,10 & 1,51 & 5,23 & 8,08 & 1,26 & 2,01 & 0,88 & 1,17 \\
\hline P. decandrum & 17,45 & 1,29 & 4,65 & 8,15 & 1,13 & 1,91 & 0,93 & 1,02 \\
\hline P. divaricatum subsp. divaricatum & 22,43 & 1,19 & 4,89 & 9,24 & 1,11 & 2,04 & 0,92 & 1,33 \\
\hline P. divaricatum subsp. fumarium & 24,15 & 1,64 & 4,47 & 7,64 & 1,26 & 1,80 & 0,86 & 0,97 \\
\hline P. elegans & 19,36 & 1,56 & 4,39 & 8,52 & 1,29 & 1,85 & 0,81 & 1,09 \\
\hline P. ferrugineum & 26,74 & 1,63 & 4,62 & 9,06 & 1,15 & 2,21 & 0,97 & 1,32 \\
\hline P. fimbriatum & 19,76 & 1,54 & 4,06 & 6,24 & 1,15 & 1,94 & 0,95 & 1,07 \\
\hline P. cf. gallosum & 16,18 & 1,02 & 2,81 & 4,76 & 1,05 & 1,93 & 0,94 & 1,03 \\
\hline$P$. giganteum & 17,31 & 1,52 & 5,83 & 8,92 & 1,17 & 1,91 & 0,88 & 1,09 \\
\hline P. grandifolium & 14,41 & 1,45 & 5,08 & 7,63 & 1,08 & 1,99 & 0,86 & 1,17 \\
\hline P. guianense subsp. pilosissimum & 16,24 & 1,30 & 3,88 & 7,74 & 1,18 & 2,35 & 1,11 & 1,28 \\
\hline P. hebetatum & 19,21 & 1,63 & 5,31 & 8,17 & 1,30 & $\mathrm{i}, 86$ & 0,91 & 1,00 \\
\hline P. heptaphyllum & 14,90 & 1,24 & 5,54 & 9,39 & 0,95 & 1,99 & 0,84 & 1,19 \\
\hline P. insigne & 30,04 & 2,12 & 4,64 & 10,02 & 1,02 & 1,82 & 0,90 & 0,96 \\
\hline P. cf. leptostachum & 17,23 & 1,46 & 3,25 & 8,14 & 1,09 & 1,95 & 0,96 & 1,02 \\
\hline P. llanorum & 17,63 & 1,48 & 4,57 & 6,88 & 1,04 & 1,99 & 0,93 & 1,10 \\
\hline P. macrophyllum & 14,77 & 1,59 & 6,16 & 9,56 & 1,16 & 1,97 & 0,93 & 1,07 \\
\hline P. minutiflorum & 16,72 & 1,22 & 3,29 & 5,04 & 1,07 & 1,85 & 0,90 & 0,97 \\
\hline P. neglectum & 28,83 & 1,96 & 7,70 & 10,61 & 1,34 & 2,86 & 1,50 & 1,38 \\
\hline P. nervosum & 16,52 & 1,38 & 5,33 & 9,32 & 1,05 & 1,83 & 0,83 & 1,04 \\
\hline P. nitidifolium & 19,46 & 1,29 & 3,77 & 7,70 & 1,08 & 2,05 & 1,01 & 1,06 \\
\hline P. opacum subsp. rabelianum & 21,33 & 1,96 & 5,59 & 10,08 & 1,27 & 1,78 & 0,82 & 0,98 \\
\hline P. ovatum & 17,00 & 1,80 & 5,35 & 9,34 & 1,32 & 2,40 & 1,10 & 1,34 \\
\hline P. paniculatum var. paniculatum & 17,34 & 1,29 & 5,53 & 8,45 & 1,09 & 1,82 & 0,82 & 0,98 \\
\hline P. paniculatum var. riedelianum & 16,32 & 1,22 & 5,30 & 9,64 & 1,25 & 2,14 & 1,02 & 1,17 \\
\hline P. pedicellattum & 16,91 & 1,32 & 4,38 & 8,62 & 1,24 & 1,78 & 0,85 & 0,97 \\
\hline P. rubrum & 14,65 & 1,51 & 3,04 & 4,43 & 1,18 & 2,25 & 1,12 & 1,18 \\
\hline P. sagotianum & 21,96 & 1,50 & 5,29 & 8,93 & 1,21 & 2,63 & 1,30 & 1,35 \\
\hline P. spruceanum & 17,21 & 1,92 & 6,01 & 9,95 & 1,26 & 1,82 & 0,87 & 1,00 \\
\hline P. subserratum & 30,75 & 3,04 & 4,94 & 13,43 & 1,16 & 1,93 & 0,91 & 1,07 \\
\hline P. tenuifolium var. herbertii & 26,39 & 1,65 & 5,80 & 8,85 & 1,15 & 3,17 & 1,76 & 1,44 \\
\hline P. trifoliolatum & 17,85 & 1,34 & 4,62 & 8,99 & 1,16 & 1,88 & 0,87 & 1,07 \\
\hline P. unifoliolatum & 15,34 & 1,49 & 5,27 & 7,57 & 1,13 & 1,98 & 0,96 & 1,04 \\
\hline P. vestitum & 22,83 & 1,56 & 4,92 & 8,00 & 1,05 & 1,84 & 0,89 & 0,97 \\
\hline
\end{tabular}




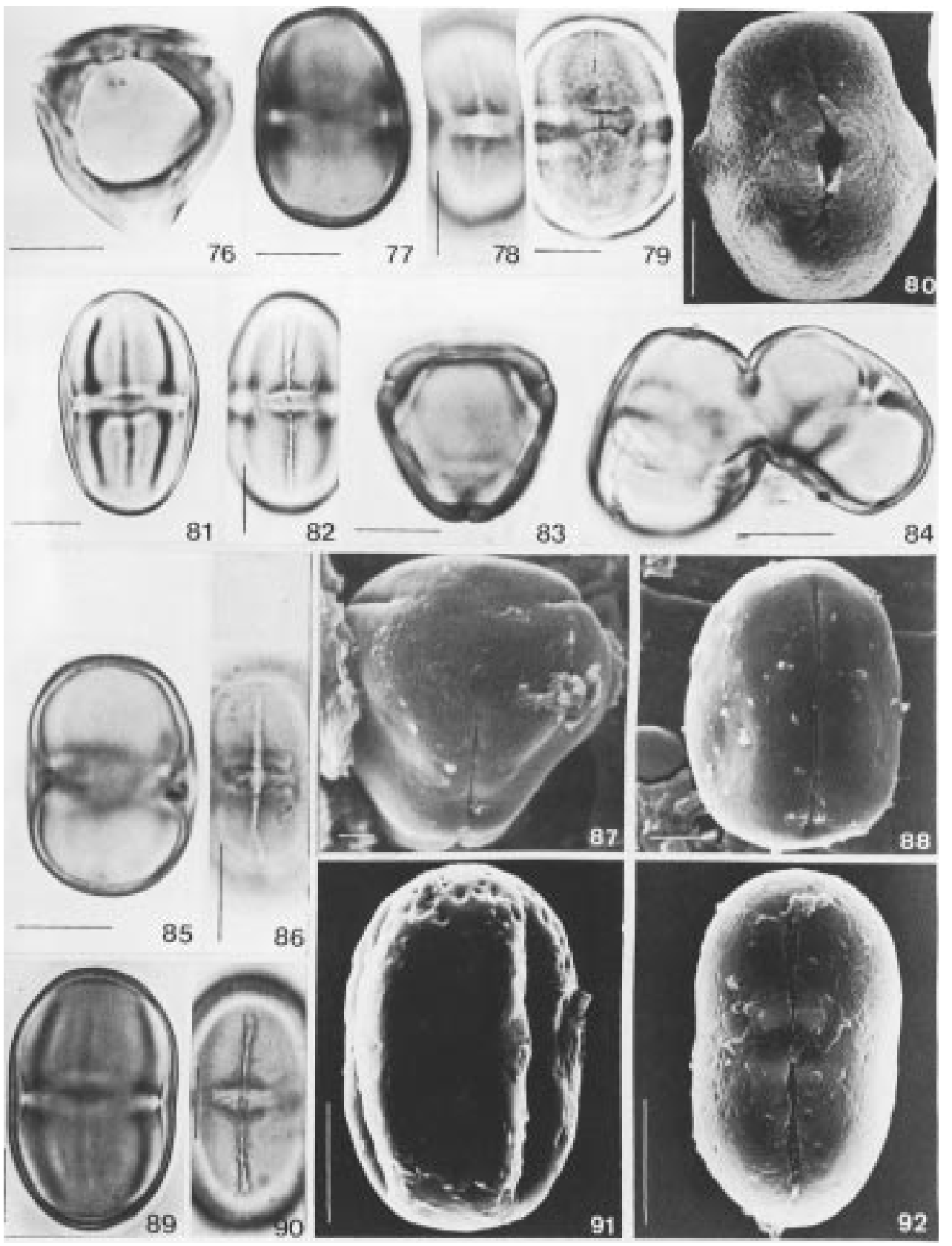

Figuras 76-92. Fotomicrografias e elétron-micrografias dos grãos de pólen de espécies de Protium. 76-78. P. decandrum. 76. Vista polar, contorno. 77-78. Vista equatorial, contorno (77), detalhe da abertura, endoabertura elíptica (78). 79-80. P. divaricatum subsp. divaricatum. 79. Vista equatorial, cólporo, endoabertura retangular constricta no centro. 80. MEV: cólporo, sexina microrreticulada, muros ondulados (escala $=8 \mu \mathrm{m}$ ). 81-82. P. divaricatum subsp. fumarium. Vista equatorial, cólporo, endoabertura retangular (81), corte óptico (82). 83-88. P. elegans. 83. Vista polar, contorno; 84. Grãos de pólen geminados; 85-86. Vista equatorial, corte óptico (85), detalhe da abertura, endoabertura elíptica (86); 87-88. MEV. 87. Vista polar, sexina psilada (escala $=2 \mu \mathrm{m}$ ); 88. Vista equatorial, abertura (escala - $5 \mu \mathrm{m}$ ); 89-92. P. ferrugineum. 89-90. Vista equatorial, corte óptico (89), detalhe da abertura (90); 91-92. MEV (escalas $=10 \mu \mathrm{m})$ : vista equatorial, sexina psilado-perfurada (91), mesocolpo, perfurações maiores no pólo (92). Escala das fotomicrografias $=10 \mu \mathrm{m}$. 

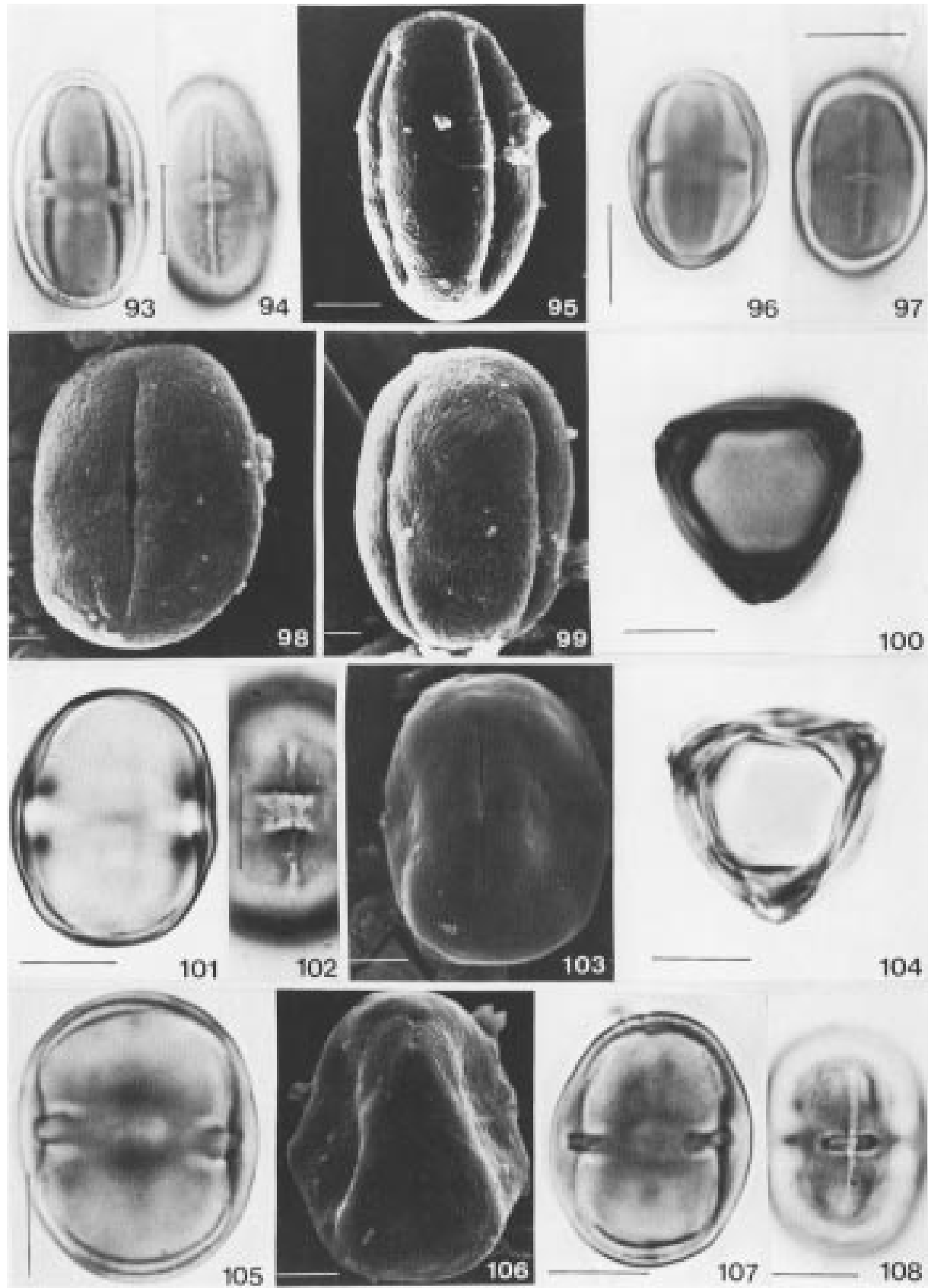

Figuras 93-108. Fotomicrografias e elétron-micrografias dos grãos de pólen de espécies de Protium. 93-95. P fimbriatum. 93-94. Vista equatorial, corte óptico (93), detalhe da abertura, endoabertura elíptica (94); 95. MEV. vista equatorial, sexina estriada $($ escala $=2 \mu \mathrm{m})$; 96-99. P. cf. gallosum. 96-97. Vista equatorial, corte óptico (96), detalhe da abertura (97); 98-99. MEV (escalas $=2 \mu \mathrm{m}$ ): vista equatorial, abertura (98); mesocolpo, sexina estriada (99). 100-103. P. giganteum. 100. Vista polar, contorno; 101-102. Vista equatorial, corte óptico (101), detalhe da abertura, endoabertura retangular (102); 103. MEV: vista equatorial, sexina psilada (escala $=5 \mu \mathrm{m}) .104-106$. P. grandifolium. 104. Vista polar, contorno; 105 . Vista equatorial, corte óptico; 106. MEV: vista equatorial, sexina psilada (escala $=5$ $\mu \mathrm{m})$. 107-108. P. guianense subsp. pilosissimum. Vista equatorial, corte óptico (107), detalhe do cólporo, endoabertura elíptica (108). Escala das fotomicrografias $=10 \mu \mathrm{m}$. 

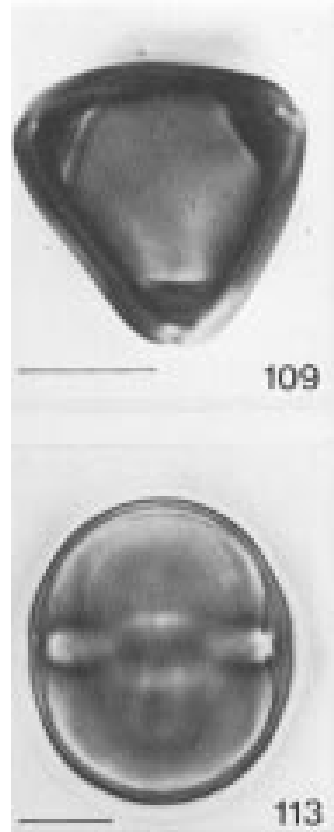

113
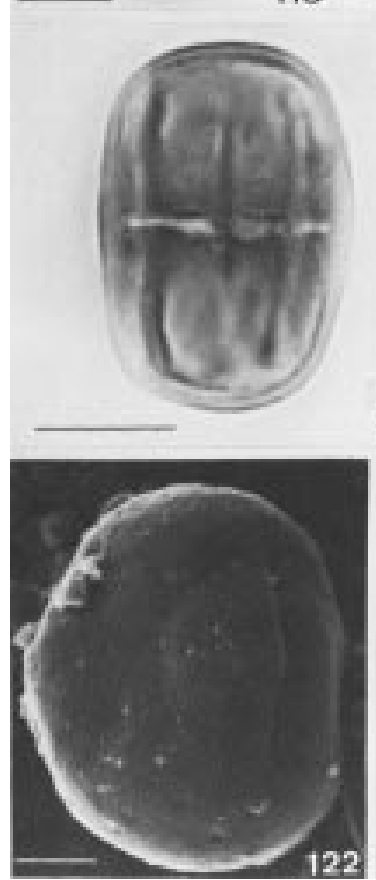
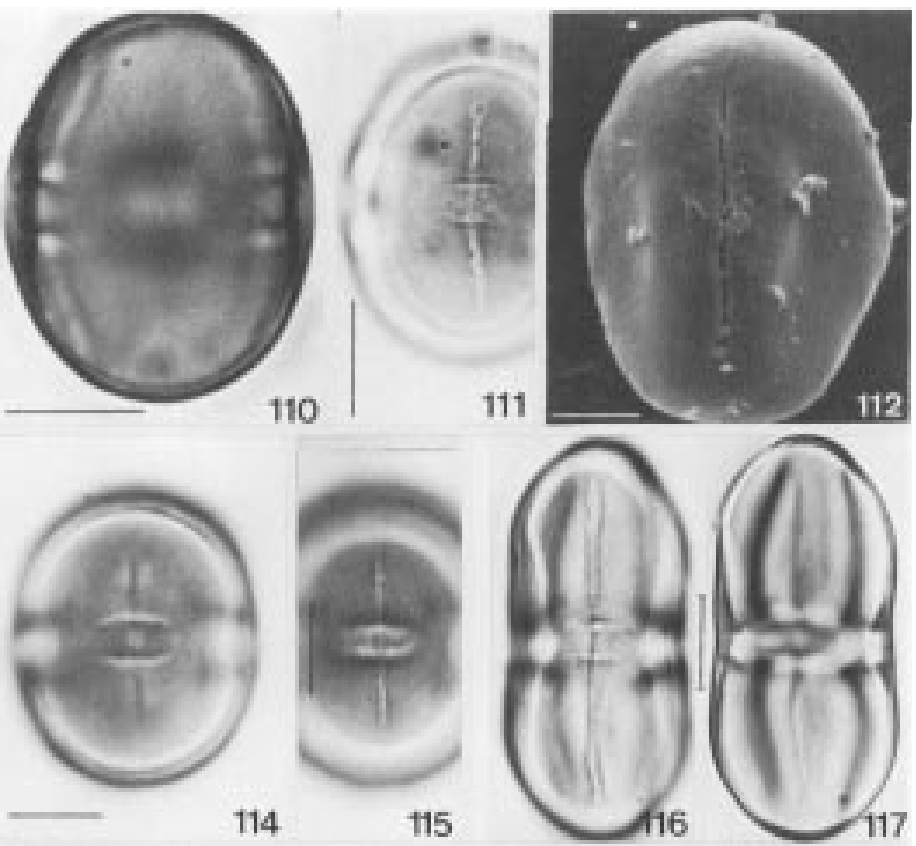

115
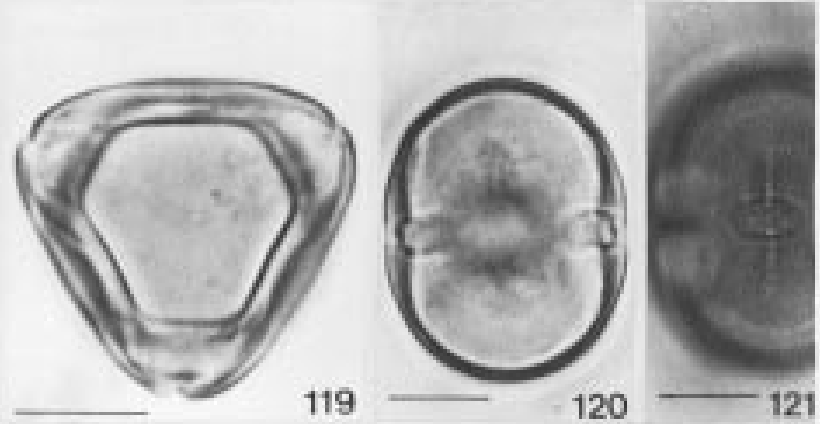

118
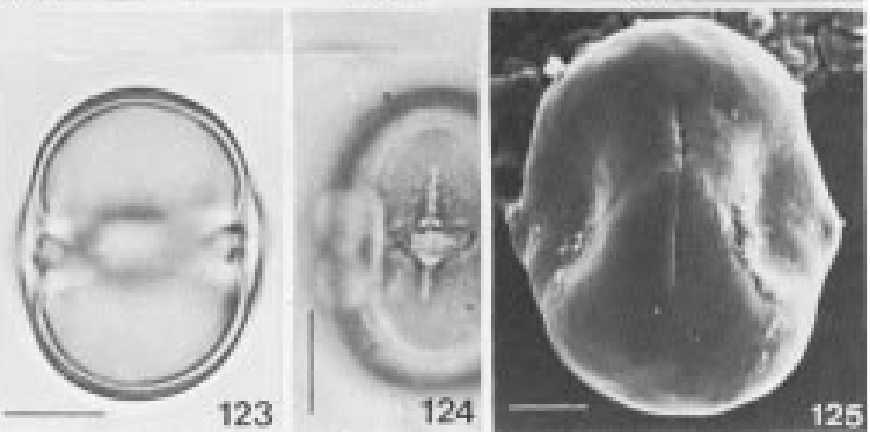

Figuras 109-125. Fotomicrografias e elétron-micrografias dos grãos de pólen de espécies de Protium. 109-112. P. hebetatum. 109. Vista polar, contorno; 110- 111 . Vista equatorial, corte óptico (110), cólporo, endoabertura retangular (111); 112. MEV: vista equatorial, sexina psilada $($ escala $=5 \mu \mathrm{m})$. 113-115. P. heptaphyllum. Vista equatorial, corte óptico (113), endoabertura elíptica (114), cólporo (115). 116-117. P. insigne. Vista equatorial, cólporo e superfície (116), contorno (117). 118. P. cf. leptostachyum. vista equatorial. 119-122. P. llanorum. 119-120. Contorno em vista polar (119) e em vista equatorial (120); 121. Detalhe do cólporo, endoabertura elíptica. 122. MEV: vista equatorial, sexina psilada $($ escala $=5 \mu \mathrm{m}) .123-125 . P$. macrophyllum. 123-124. Vista equatorial, corte óptico (123), detalhe do brevicolpo, endoabertura elíptica (124); 125. MEV: vista equatorial, sexina psilada (escala $=5 \mu \mathrm{m})$. Escala das fotomicrografias $=10 \mu \mathrm{m}$. 
m. ca. $0,75 \mu \mathrm{m})$; para $P$. crassipetalum os lúmens e os muros têm aproximadamente as mesmas dimensões nas regiões polar (1. ca. 0,99 $\mu \mathrm{m}$; m. ca. $0,81 \mu \mathrm{m}$ ) e equatorial (1. ca. $0,98 \mu \mathrm{m}$; m. ca. $0,85 \mu \mathrm{m}$ ).

Em $P$. neglectum (figuras 130-132) os grãos de pólen são microrreticulados sob microscopia óptica e psilado-perfurados ao MEV, esta diferença indica a necessidade de estudos complementares ao MET a fim de esclarecer a estrutura da exina; os resultados obtidos sugerem que a sexina é formada por uma camada de columelas ramificadas e um teto muito fino que por transparência mostra a disposição das columelas infratectais com uma distribuição semelhante a um microrretículo.

Comentários - Em P. insigne e P. sagotianum o colpo é constricto no centro (figuras 116 e 167); em $P$. cf. leptostachyum e $P$. trifoliolatum as endoaberturas são pseudo-sinclinoradas (figuras 118 e 180); em $P$. sagotianum a sexina microrreticulada mostrou lúmens maiores dispersos na superfície (figuras 164 e 165); em $P$. insigne o contorno, em vista equatorial, é ligeiramente côncavo no equador (figuras $116 \mathrm{e}$
117); foram observados grãos de pólen germinados em P. elegans (figura 84) e em P. minutiflorum.

Em muitas espécies foram registradas baixas porcentagens $(<10 \%)$ ou raros grãos de pólen 2-colporados e 4-colporados; estes últimos são, geralmente, loxocolporados (com as aberturas convergindo em pares) e apresentam o contorno em forma de "pera" (figura 34). Esta variação no número das aberturas foi confirmada nos materiais de comparação.

As medidas dos materiais de comparação registradas na tabela 8 permitem observar que dificilmente o tamanho dos grãos de pólen poderá ser utilizado na separação taxonômica, já que na maioria dos táxons é significante a diferença encontrada entre os espécimes de uma mesma espécie. Os dados mostram que embora ocorra uma certa variabilidade nos diâmetros dos grãos de pólen, a classe de tamanho (pequeno ou médio) é mantida entre o material padrão e os de comparação de um mesmo táxon.

A tabela 8 mostra ainda que a forma dos grãos de pólen dos materiais de comparação manteve-se igual à do material padrão, na maioria dos táxons.

Tabela 8. Média aritmética das medidas dos grãos de pólen dos materiais de comparação de espécies de Protium $(\mathrm{n}=10)$.

\begin{tabular}{|c|c|c|c|c|}
\hline \multirow{2}{*}{ Espécies } & \multicolumn{2}{|c|}{ Vista equatorial $(\mu \mathrm{m})$} & \multirow{2}{*}{$\begin{array}{l}\text { Vista polar }(\mu \mathrm{m}) \\
\text { Diâm. equatorial }\end{array}$} & \multirow{2}{*}{$\mathrm{P} / \mathrm{E}$} \\
\hline & Diâm. polar & Diâm. equatorial & & \\
\hline \multicolumn{5}{|l|}{ P. amplum } \\
\hline (Gentry et al. 57032) & $29,00^{\mathrm{a}}$ & 21,91 & 21,97 & $1,32^{\mathrm{b}}$ \\
\hline \multicolumn{5}{|l|}{ P. apiculatum } \\
\hline (Cid Ferreira et al. 8227) & $26,40^{\mathrm{a}}$ & 19,52 & 19,80 & 1,35 \\
\hline (Pires \& Silva 1471) & $26,38^{a}$ & $17,58^{\mathrm{a}}$ & $17,77^{\mathrm{a}}$ & 1,50 \\
\hline (Pires \& Silva 1481) & 28,53 & 19,42 & 20,08 & 1,47 \\
\hline (Rabelo \& Cardoso 3154) & 22,30 & 15,74 & 16,29 & 1,42 \\
\hline \multicolumn{5}{|l|}{ P. aracouchini } \\
\hline (Brand \& Ascanio 238) & $26,02^{\mathrm{a}}$ & 20,33 & 20,43 & 1,28 \\
\hline (Cárdenas 1655) & $25,97^{\mathrm{a}}$ & 20,86 & $19,31^{\mathrm{a}}$ & 1,25 \\
\hline (Cárdenas 1777) & 24,31 & 20,00 & $19,01^{\text {a }}$ & 1,22 \\
\hline (Teixeira et al. 1210) & $26,18^{a}$ & 16,19 & 16,26 & $1,62^{\mathrm{b}}$ \\
\hline (Thomas et al. 5152) & 26,73 & 15,96 & 15,86 & $1,68^{b}$ \\
\hline (Ramírez \& Cárdenas 1182) & 23,09 & 19,07 & - & 1,21 \\
\hline (Ramírez \& Cárdenas 1292) & 26,94 & 22,07 & 21,81 & 1,22 \\
\hline \multicolumn{5}{|l|}{ P. brasiliense } \\
\hline (Berg et al. 18401) & 24,54 & 19,72 & 19,87 & $1,24^{\mathrm{b}}$ \\
\hline (Henrique et al. 6627) & 29,75 & 21,12 & 21,62 & $1,41^{\mathrm{b}}$ \\
\hline (Hoehne 5824) & $27,90^{\mathrm{a}}$ & 22,06 & 20,86 & $1,27^{\mathrm{b}}$ \\
\hline (Pirani et al. 7464) & $28,86^{\mathrm{a}}$ & 22,20 & 21,62 & $1,30^{\mathrm{b}}$ \\
\hline \multicolumn{5}{|l|}{ P. calanense } \\
\hline (Soejarto \& Villa 2787) & 26,06 & 15,35 & - & 1,70 \\
\hline \multicolumn{5}{|l|}{ P. carnosum } \\
\hline (Cid Ferreira 8790) & 18,59 & 18,93 & 18,94 & $0,98^{\mathrm{b}}$ \\
\hline (Nee 34916) & 19,03 & 18,70 & 19,10 & $1,02^{\mathrm{b}}$ \\
\hline
\end{tabular}




\begin{tabular}{|c|c|c|c|c|}
\hline \multirow{2}{*}{ Espécies } & \multicolumn{2}{|c|}{ Vista equatorial $(\mu \mathrm{m})$} & \multirow{2}{*}{$\begin{array}{l}\text { Vista polar }(\mu \mathrm{m}) \\
\text { Diâm. equatorial }\end{array}$} & \multirow{2}{*}{$\mathrm{P} / \mathrm{E}$} \\
\hline & Diâm. polar & Diâm. equatorial & & \\
\hline (Teixeira et al. 585) & $17,29^{\mathrm{a}}$ & 17,00 & $17,47^{\mathrm{a}}$ & $1,02^{\mathrm{b}}$ \\
\hline \multicolumn{5}{|l|}{ P. cranipyrenum } \\
\hline (Monsalve 1723) & 30,63 & 22,70 & 21,33 & 1,35 \\
\hline \multicolumn{5}{|l|}{ P. crassipetalum } \\
\hline (Campbell et al. 21923) & 19,52 & $19,15^{\mathrm{a}}$ & 19,20 & 1,02 \\
\hline (Cid Ferreira 8089) & 20,31 & 19,50 & 19,34 & 1,04 \\
\hline (Daly 5129) & 19,64 & 19,55 & 19,36 & 1,01 \\
\hline (Thomas et al. 5112) & $21,16^{\mathrm{a}}$ & 19,95 & $19,87^{\mathrm{a}}$ & 1,06 \\
\hline (Thomas et al. 5303) & 18,81 & 18,37 & 18,97 & 1,02 \\
\hline \multicolumn{5}{|l|}{ P. crenatum } \\
\hline (Rodríguez 1534) & 26,95 & 19,92 & - & 1,35 \\
\hline \multicolumn{5}{|l|}{ P. dawsonii } \\
\hline (Silva \& Rosário 5039) & 28,18 & $23,79^{\mathrm{a}}$ & 23,97 & 1,18 \\
\hline \multicolumn{5}{|l|}{ P. decandrum } \\
\hline (Daly et al. 762) & 26,64 & 18,19 & 18,43 & 1,47 \\
\hline (Revilla et al. 8552) & 29,48 & 18,88 & 18,64 & 1,56 \\
\hline (Lima et al. 8573) & 24,64 & 18,24 & 18,18 & 1,35 \\
\hline (Rodrigues et al. 4825) & 25,05 & $19,46^{\mathrm{a}}$ & - & $1,29^{\mathrm{b}}$ \\
\hline \multicolumn{5}{|c|}{ P. divaricatum subsp. divaricatum } \\
\hline (Daly et al. 4130) & 36,73 & 20,84 & - & $1,76^{\mathrm{b}}$ \\
\hline (Dionizia et al. 88) & 30,34 & 16,79 & - & $1,81^{\mathrm{b}}$ \\
\hline (Fróes 26400) & 31,22 & 19,75 & - & $1,58^{\mathrm{b}}$ \\
\hline (Soares 12) & 30,18 & 16,85 & - & $1,79^{\mathrm{b}}$ \\
\hline \multicolumn{5}{|l|}{ P. elegans } \\
\hline (Alvarez et al. 1017) & 28,37 & 22,17 & - & $1,28^{\mathrm{a}}-\mathrm{a}$ \\
\hline (Prance et al. 12128) & $25,10^{\mathrm{a}}$ & 14,85 & 15,96 & 1,69 \\
\hline \multicolumn{5}{|l|}{ P. ferrugineum } \\
\hline (García-Barriga 13837) & 30,67 & 21,09 & - & 1,45 \\
\hline (Monsalve 1302) & $33,80^{\mathrm{a}}$ & 20,22 & 20,10 & 1,67 \\
\hline (Pipdy et al. 6725) & 32,10 & 21,37 & 21,33 & 1,50 \\
\hline (Prance et al. 29437) & 32,36 & 23,27 & 23,42 & 1,39 \\
\hline (Vieira et al. 288) & 30,70 & 21,27 & 21,49 & 1,44 \\
\hline \multicolumn{5}{|l|}{ P. fimbriatum } \\
\hline (Acero \& Rodrigues 983) & 20,93 & $14,13^{\mathrm{a}}$ & - & 1,48 \\
\hline (Amaral et al. 141) & 19,36 & 13,11 & - & 1,48 \\
\hline (Mota \& Coêlho 96) & 18,95 & 12,36 & _- & 1,53 \\
\hline (Vieira et al. 46) & 22,83 & $14,63^{\mathrm{a}}$ & 15,03 & 1,56 \\
\hline \multicolumn{5}{|l|}{ P. cf. gallosum } \\
\hline (Cid Ferreira et al. 8208) & 27,48 & 19,96 & 20,64 & 1,38 \\
\hline \multicolumn{5}{|l|}{ P. grandifolium } \\
\hline (Cid Ferreira et al. 787) & 26,53 & 22,15 & 21,03 & 1,20 \\
\hline (Rodrigues 1924) & 28,20 & $20,21^{\mathrm{a}}$ & $19,66^{\mathrm{a}}$ & $1,40^{\mathrm{b}}$ \\
\hline \multicolumn{5}{|l|}{ P. hebetatum } \\
\hline (Coêlho \& Hugo 99652) & 25,91 & $19,08^{\mathrm{a}}$ & - & $1,36^{\mathrm{a}}$ \\
\hline (Miller 641) & 28,00 & 20,29 & 19,87 & $1,38^{\mathrm{b}}$ \\
\hline (Miller 643) & 25,88 & 20,53 & 20,42 & 1,26 \\
\hline \multicolumn{5}{|l|}{ P. heptaphyllum } \\
\hline (Betancur \& Porras 1512) & $29,79^{\mathrm{a}}$ & $25,32^{\mathrm{a}}$ & $23,84^{\mathrm{a}}$ & 1,18 \\
\hline (Cordeiro \& Pirani 6528) & 28,77 & 23,99 & 22,78 & 1,20 \\
\hline (Fróes 30341) & 31,05 & $24,45^{\mathrm{a}}$ & 23,40 & 1,27 \\
\hline (Heringer 18629) & $29,74^{\mathrm{a}}$ & 23,66 & $23,82^{\mathrm{a}}$ & 1,26 \\
\hline (Macêdo 734) & 27,97 & $24,69^{\mathrm{a}}$ & $24,41^{\mathrm{a}}$ & $1,13^{b}$ \\
\hline (Rodrigues 62) & 30,79 & 26,79 & $24,95^{\mathrm{a}}$ & 1,15 \\
\hline (Rornán 62) & $29,39^{\mathrm{a}}$ & $24,86^{\mathrm{a}}$ & 23,53 & 1,18 \\
\hline P. insigne & & & & \\
\hline (Romero-Castañeda 538) & $31,66^{\mathrm{a}}$ & 22,41 & - & 1,41 \\
\hline (Santos 514) & $31.53^{\mathrm{a}}$ & 25,22 & 24.74 & $1,25^{\mathrm{b}}$ \\
\hline
\end{tabular}




\begin{tabular}{|c|c|c|c|c|}
\hline \multirow{2}{*}{ Espécies } & \multicolumn{2}{|c|}{ Vista equatorial $(\mu \mathrm{m})$} & \multirow{2}{*}{$\begin{array}{l}\text { Vista polar }(\mu \mathrm{m}) \\
\text { Diâm. equatorial }\end{array}$} & \multirow{2}{*}{$\mathrm{P} / \mathrm{E}$} \\
\hline & Diâm. polar & Diâm. equatorial & & \\
\hline \multicolumn{5}{|l|}{ P. macrophyllum } \\
\hline (Monsalve 616) & 25,43 & 20,82 & 18,69 & 1,22 \\
\hline \multicolumn{5}{|l|}{ P. neglectum } \\
\hline (Breteler 3656) & 27,85 & 22,33 & 22,47 & $1,25^{\mathrm{a}}$ \\
\hline (Hage \& dos Santos 1389) & 29,11 & 23,74 & 23,28 & $1,23^{\mathrm{b}}$ \\
\hline (Mello 1996) & 22,97 & 22,55 & 22,06 & $1,02^{\mathrm{b}}$ \\
\hline (Prance et al. 8438) & 21,91 & 22,14 & 22,75 & $0,99^{\mathrm{b}}$ \\
\hline \multicolumn{5}{|l|}{ P. nervosum } \\
\hline (Cuatrecasas 14147) & 29,66 & 25,48 & - & 1,16 \\
\hline (Gentry 48012) & 30,53 & 20,99 & 20,73 & $1,46^{\mathrm{b}}$ \\
\hline (Monsalve 2085) & $28,31^{\mathrm{a}}$ & 20,78 & 19,87 & $1,36^{\mathrm{b}}$ \\
\hline \multicolumn{5}{|l|}{ P. nitidifolium } \\
\hline (Cid Ferreira et al. 8208) & 27,51 & $17,96^{\mathrm{a}}$ & $18,91^{\mathrm{a}}$ & 1,53 \\
\hline (Pires \& Silva 1470) & 26,13 & $17,97^{\mathrm{a}}$ & 18,24 & 1,45 \\
\hline (Prance et al. 22671) & 20,10 & 14,34 & 14,07 & 1,40 \\
\hline (Prance et al. 22989) & 25,69 & 16,98 & $18,61^{\mathrm{a}}$ & 1,51 \\
\hline \multicolumn{5}{|l|}{ P. ovatum } \\
\hline (Azevedo 50) & 30,74 & 24,62 & $23,36^{\mathrm{a}}$ & 1,25 \\
\hline (Hatsbach \& Guimarães 21750) & 29,17 & 22,91 & 23,68 & 1,27 \\
\hline (Heringer et al. 6397) & 29,97 & $23,85^{\mathrm{a}}$ & $23,52^{\mathrm{a}}$ & 1,26 \\
\hline (Mantovani 1832) & 29,91 & 25,19 & 24,26 & 1,19 \\
\hline (Mattos 12243) & 32,13 & 24,49 & 22,57 & 1,31 \\
\hline (Pirani et al. 1635) & 30,91 & 26,93 & 25,45 & 1,15 \\
\hline \multicolumn{5}{|l|}{ P. paniculatum var. paniculatum } \\
\hline (Londoño 1202) & 30,82 & 24,18 & 23,72 & 1,28 \\
\hline (Prance et al. 16019) & 26,87 & $20,50^{\mathrm{a}}$ & $19,81^{\mathrm{a}}$ & 1,31 \\
\hline (Soares 29) & 28,61 & 20,70 & $20,37^{\mathrm{a}}$ & $1,38^{\mathrm{b}}$ \\
\hline \multicolumn{5}{|l|}{ P. paniculatum var. riedelianum } \\
\hline (Cid Ferreira et al. 8254) & $27,13^{\mathrm{a}}$ & 20,87 & 19,91 & $1,30^{\mathrm{b}}$ \\
\hline (Daly et al. 827) & 27,80 & 20,44 & 21,07 & 1,36 \\
\hline (Pires et al. 721) & 27,85 & 21,43 & 20,65 & $1,30^{\mathrm{b}}$ \\
\hline (Prance et al. 15899) & 25,70 & 20,16 & 19,36 & $1,28^{\mathrm{b}}$ \\
\hline (Ramos 1039) & $27,48^{\mathrm{a}}$ & $19,69^{\mathrm{a}}$ & 19,34 & 1,40 \\
\hline \multicolumn{5}{|l|}{ P. sagotianum } \\
\hline (Cárdenas 2137) & $28,05^{\mathrm{a}}$ & 24,15 & $25,29^{\mathrm{a}}$ & 1,16 \\
\hline (Idrobo \& Schultes 1317) & 29,36 & $24,95^{\mathrm{a}}$ & $25,68^{\mathrm{a}}$ & 1,18 \\
\hline (Nee 34579) & 31,71 & 25,39 & 23,46 & 1,25 \\
\hline \multicolumn{5}{|l|}{ P. spruceanum } \\
\hline (Eiten \& Eiten 9177) & $28,52^{\mathrm{a}}$ & $21,98^{\mathrm{a}}$ & $21,60^{\mathrm{a}}$ & 1,30 \\
\hline (Mantovani 1041) & 28,23 & $22,51^{\mathrm{a}}$ & $21,38^{\mathrm{a}}$ & 1,25 \\
\hline (Mattos \& Mattos 8206) & $29,11^{\mathrm{a}}$ & 23,86 & 21,75 & 1,22 \\
\hline (Mattos 15062) & 28,34 & 21,68 & $21,15^{\mathrm{a}}$ & 1,31 \\
\hline \multicolumn{5}{|l|}{ P. subserratum } \\
\hline (Miller 290) & 35,80 & $21,87^{\mathrm{a}}$ & 23,02 & 1,64 \\
\hline (Silva et al. 1026) & 32,98 & $21,99^{\mathrm{a}}$ & - & 1,50 \\
\hline (Souza et al. 183) & 26,12 & 19,43 & 18,98 & 1,34 \\
\hline (Teixeira et al. 937) & 37,06 & $22,72^{\mathrm{a}}$ & 24,69 & 1,63 \\
\hline \multicolumn{5}{|l|}{ P. tenuifolium var. herbertii } \\
\hline (Smith 405) & 30,52 & $25,41^{\mathrm{a}}$ & 25,92 & $1,20^{\mathrm{b}}$ \\
\hline \multicolumn{5}{|l|}{ P. trifoliolatum } \\
\hline (Rodrigues \& Coêlho 7370) & 23,32 & 16,96 & 17,64 & 1,38 \\
\hline \multicolumn{5}{|l|}{ P. unifoliolatum } \\
\hline (da Silva et al. 258) & 28,86 & 21,25 & 20,76 & 1,36 \\
\hline (Eiten \& Eiten 9202) & $27,62^{\mathrm{a}}$ & 20,47 & 20,84 & 1,35 \\
\hline \multicolumn{5}{|l|}{ P. vestitum } \\
\hline (Cuatrecasas 14193) & $31,91^{\mathrm{a}}$ & 22,72 & 21,58 & 1,40 \\
\hline
\end{tabular}

Comparando com o material padrão, os valores assinalados indicam: ${ }^{\text {a }}$ dentro do I.C.; ${ }^{b}$ forma diferente. 


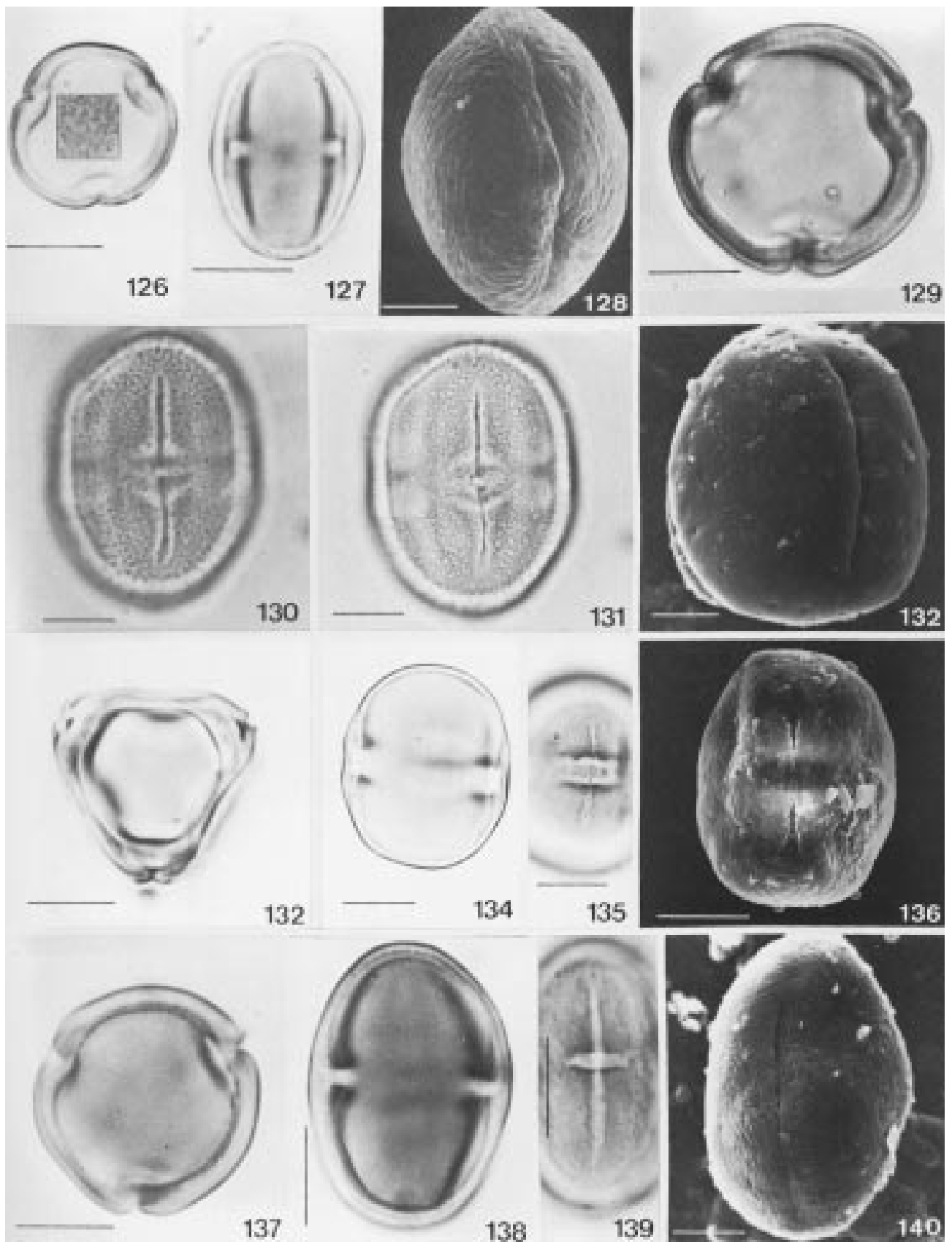

Figuras 126-140. Fotomicrografias e elétron-micrografias dos grãos de pólen de espécies de Protium. 126-128. P minutiflorum. 126. Vista polar, contorno, detalhe da ornamentação no centro do grão de pólen; 127. Vista equatorial, corte óptico; 128. MEV: vista equatorial, sexina estriada $($ escala $=10 \mu \mathrm{m}) ; 129-132$. P. neglectum. 129. Vista polar, contorno. 130-131. Análise de L.O. mostrando a sexina microrreticulada; 132. MEV: vista equatorial, sexina psilada com perfurações esparsas (escala = $5 \mu \mathrm{m})$. 133-136. P. nervosum. 133. Vista polar, contorno; 134-135. Vista equatorial, contorno (134), detalhe do cólporo (135); 136. MEV: vista equatorial, sexina psilado-perfurada, abertura circundada por área psilada (escala $=10 \mu \mathrm{m}) ; 137-140$. P. nitidifolium. 137. Vista polar, contorno; 138-139. Vista equatorial, corte óptico (138), detalhe do cólporo (139); 140. MEV: vista equatorial, sexina estriada (escala $=5 \mu \mathrm{m}$ ). Escala das fotomicrografias $=10 \mu \mathrm{m}$. 


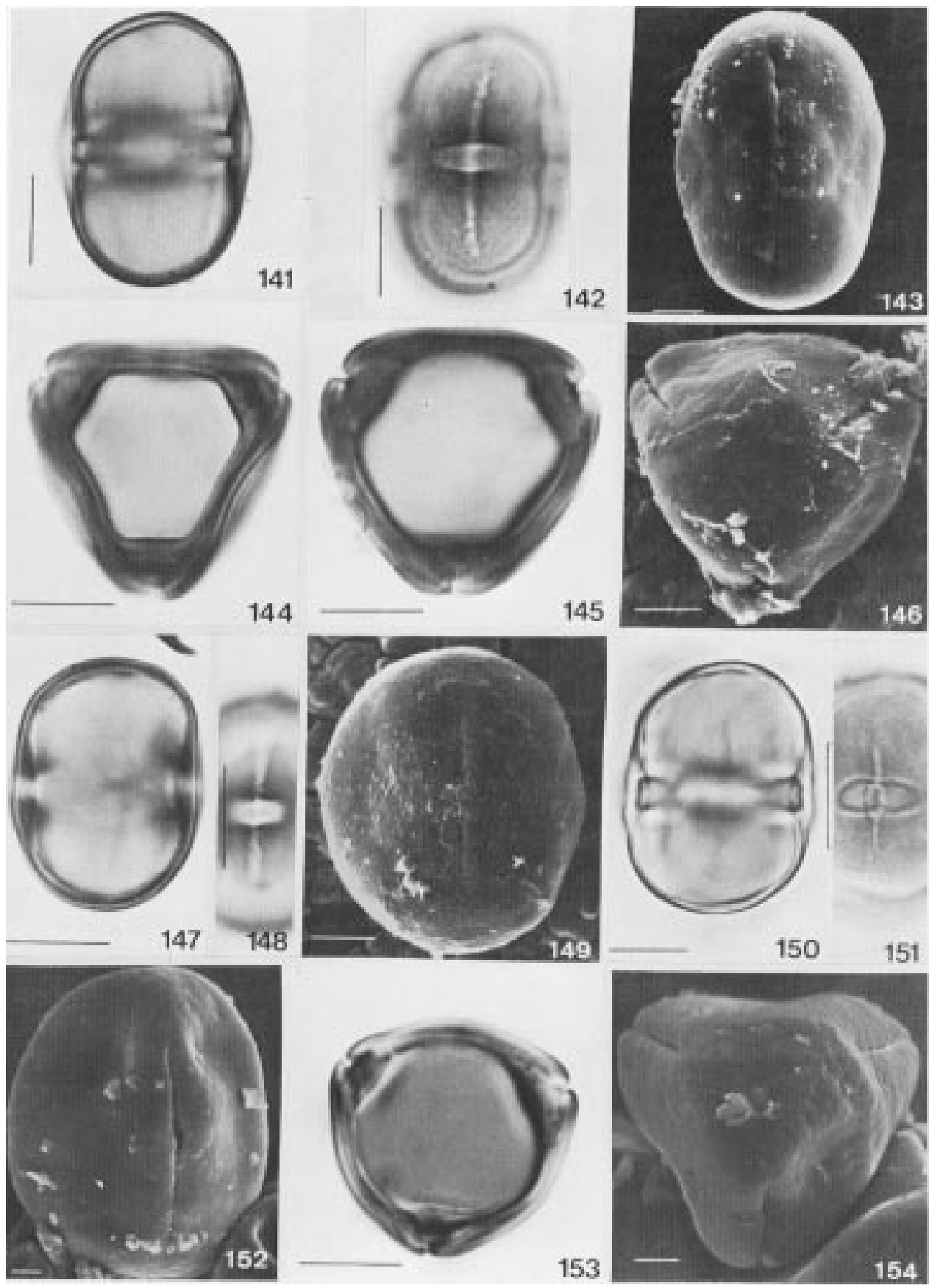

Figuras 141-154. Fotomicrografias e elétron-micrografias dos grãos de pólen de espécies de Protium. 141-143. P. opacum subsp. rabelianum. 141-142. Vista equatorial, corte óptico (141), cólporo, endoabertura elíptica (142); 143. MEV: vista equatorial, sexina psilada $($ escala $=5 \mu \mathrm{m}) ; 144-149$. P. ovatum. 144-145. Vista polar em diferentes focos; 146. MEV: vista polar, sexina psilada (escala $=5 \mu \mathrm{m}) ; 147-148$. Vista equatorial, corte óptico (147), detalhe do cólporo (148); 149. MEV: vista equatorial, sexina psilada $($ escala $=5 \mu \mathrm{m}) .150-154$. P. paniculatum var. paniculatum. $150-151$. Vista equatorial, corte óptico (150); cólporo, endoabertura elíptica (151); 152. MEV: vista equatorial, sexina psilada (escala - $2 \mu \mathrm{m}$ ); 153. Vista polar, contorno; 154. MEV: vista polar, sexina psilada com perfurações (escala $=2 \mu \mathrm{m}$ ). Escala das fotomicrografias $=10 \mu \mathrm{m}$. 


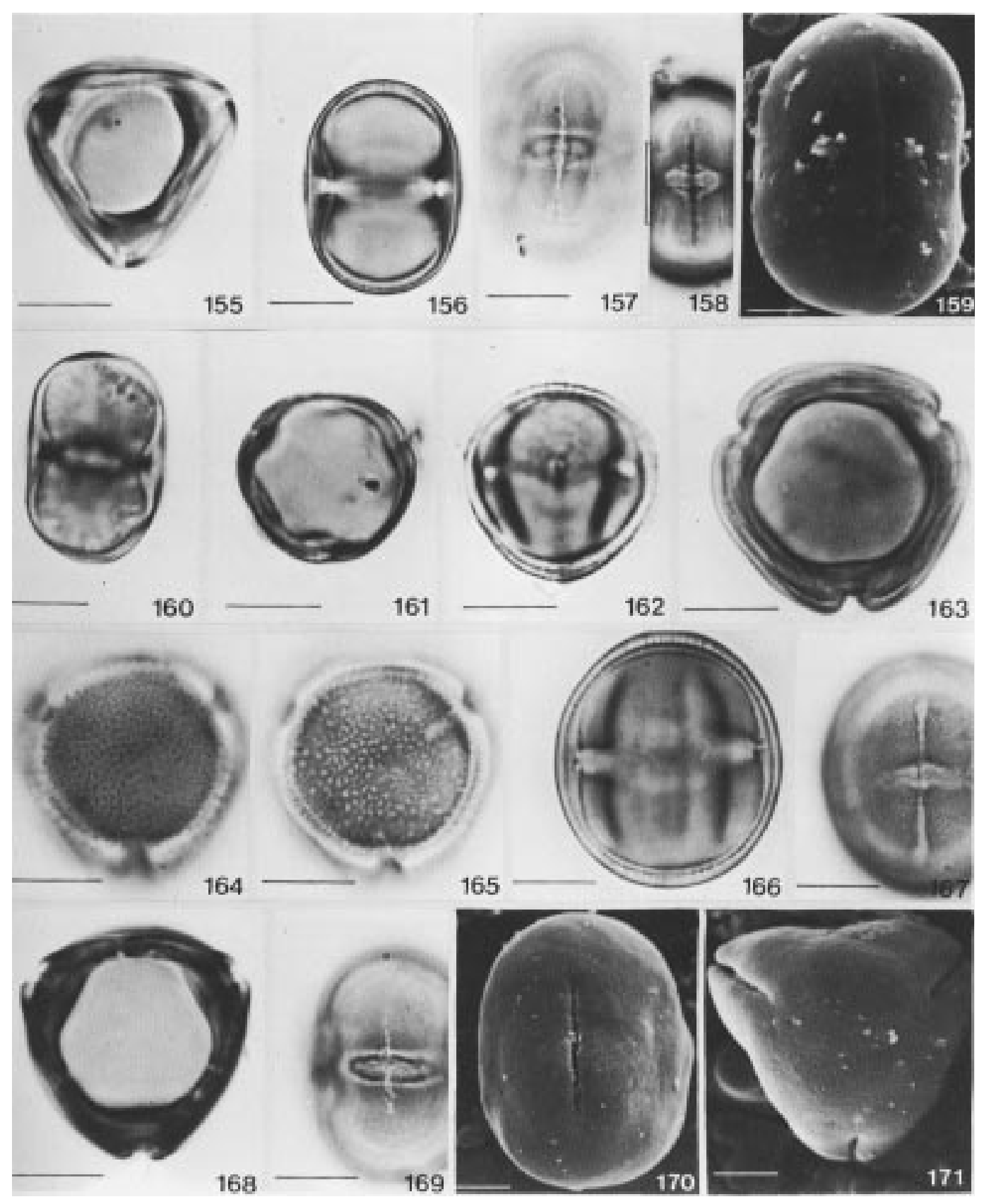

Figuras 155-171. Fotomicrografias e elétron-micrografias dos grãos de pólen de espécies de Protium. 155-159. P. paniculatum var. riedelianum. 155. Vista polar, contorno; 156-158. Vista equatorial, corte óptico (156), detalhe do cólporo (157), endoabertura elíptica (158); 159. MEV: vista equatorial, sexina psilada (escala $=5 \mu \mathrm{m}) ; 160 . P$. pedicellatum: vista equatorial, contorno. 161-162. P. rubrum. 161. Vista polar, contorno; 162. Vista equatorial, corte óptico. 163-167. P. sagotianum. 163. Vista polar, corte éptico; 164-165. Análise de L.O mostrando a sexina microrreticulada, com lúmens maiores dispersos na superfície; 166-167. Vista equatorial, corte óptico (166), cólporo, endoabertura elíptica (167). 168-171. P. spruceanum. 168. Vista polar, contorno, 169. Vista equatorial, cólporo, endoabertura elíptica; 170-171. MEV (escalas $=5 \mu \mathrm{m}$ ): vista equatorial, sexina psilada (170), vista polar (171). Escala das fotomicrografias $=10 \mu \mathrm{m}$. 
Alguns materiais de comparação apresentaram diferenças significativas nas características morfopolínicas quando comparadas com as dos materiais padrão, indicando a possibilidade de erros na identificação; assim, no caso de P. insigne (Santos 514) a exina é microrreticulada com características semelhantes às de $P$. sagotianum. Em $P$. neglectum (Mello 1996 e Prance et al. 3438) os grãos de pólen têm a exina reticulada, diferente daquela do material padrão (Romero-Castañeda 558a) que é microrreticulada em microscopia óptica (psilado-perfurada ao MEV).

Quanto aos materiais de $P$. divaricatum, $P$. guianense, $P$. paniculatum, e $P$. tenuifolium (figuras 189-204; tabela 9), não identificados ao nível infraespecífico, verificou-se que:

1. os grãos de pólen de $P$. divaricatum $(\mathrm{P} / \mathrm{E} \geq 1,71)$ com endoabertura retangular e exina psilada estão mais relacionados com àqueles de $P$. divaricatum subsp. fumarium $(\mathrm{P} / \mathrm{E}=1,81)$; diferem dos de $P$. divaricatum subsp. divaricatum $(\mathrm{P} / \mathrm{E}=1,32)$ que têm endoabertura retangular, constricta no centro e exina microrreticulada, com muros ondulados;

2. P. guianense com grãos de pólen de tamanho médio, endoabertura retangular, exina psilada sob microscopia óptica e psilado-perfurada no mesocolpo ao MEV difere de $P$. guianense subsp. pilosissimum cujos grãos de pólen são pequenos, com endoabertura elíptica e sexina psilada;

3. as características palinológicas de $P$. paniculatum são semelhantes às de $P$. paniculatum var. riedelianum; as únicas diferenças observadas foram na forma retangular da endoabertura, às vezes pseudosinclinorada e nos grãos de pólen do material Cogollo 1748 cuja forma é subprolata. Ao MEV os grãos de pólen provenientes da exsicata Chagas 21730 apresentaram sexina psilada, como em $P$. paniculatum var. riedelianum, sendo que em $P$. paniculatum var. paniculatum esta é psilado-perfurada no apocolpo; 4. os materiais estudados de P. tenuifolium mostraram características morfopolínicas similares entre si, com grãos de pólen prolato-esferoidais, exceto no espécime Quintero 2206 cuja forma é subprolata. Com relação à ornamentação microrreticulada da exina (ao MEV, com muros ondulados nos grãos de pólen da exsicata Callejas et al. 8289) há uma marcada diferença quando comparada corn aquela de $P$. tenuifolium var. herbertii com grãos de pólen psilados sob microscopia óptica e psilado-perfurados ao MEV

\section{Discussão}

Até agora não há, na literatura, dados sobre a morfologia polínica de espécies de Crepidospermum.

Tabela 9. Média aritmética das medidas dos grãos de pólen de espécies de Protium sem identificação infra-específica $(\mathrm{n}=10)$.

\begin{tabular}{|c|c|c|c|c|}
\hline \multirow{2}{*}{ Espécies } & \multicolumn{2}{|c|}{ Vista equatorial $(\mu \mathrm{m})$} & \multirow{2}{*}{$\begin{array}{l}\text { Vista polar }(\mu \mathrm{m}) \\
\text { Diâm. equatorial }\end{array}$} & \multirow{2}{*}{$\mathrm{P} / \mathrm{E}$} \\
\hline & Diâm. polar & Diâm. equatorial & & \\
\hline \multicolumn{5}{|l|}{ P. divaricatum } \\
\hline (Amaral et al. 173) & 34,78 & 19,87 & 20,72 & 1,75 \\
\hline (Cid Ferreira et al. 349) & 34,02 & 17,79 & - & 1,91 \\
\hline (Cid Ferreira \& Lima 3303) & 32,42 & 17,89 & - & 1,81 \\
\hline (Mota \& Coelho 83) & 31,48 & 18,45 & 19,49 & 1,71 \\
\hline (Prance et al. 2498) & 31,39 & 16,44 & 17,15 & 1,91 \\
\hline (Revilla et al. 7041) & 33,37 & 18,81 & - & 1,77 \\
\hline \multicolumn{5}{|l|}{ P. guianense } \\
\hline (Schultes \& Cabrera 14233) & 27,71 & 23,98 & 23,25 & 1,16 \\
\hline \multicolumn{5}{|l|}{ P. paniculatum } \\
\hline (Chagas 21730) & 29,71 & 20,55 & 19,86 & 1,45 \\
\hline (Coêlho et al. 148) & 29,02 & 21,78 & 22,17 & 1,33 \\
\hline (Cogollo 1748) & 28,67 & 22,32 & 20,80 & $1,28^{*}$ \\
\hline \multicolumn{5}{|l|}{ P. tenuifolium } \\
\hline (Callejas et al. 8289) & 26,76 & 24,75 & 25,58 & 1,08 \\
\hline (Prance et al. 17541) & 23,45 & 23,22 & 23,83 & 1,01 \\
\hline (Quintero 2206) & 32,09 & 27,77 & 26,93 & $1,16^{*}$ \\
\hline (Rabelo \& Souza 2936) & 27,87 & 24,62 & 22,38 & 1,13 \\
\hline (Rabelo et ai. 3246) & 30,10 & 26,72 & 26,34 & 1,13 \\
\hline
\end{tabular}

* indica forma diferente 


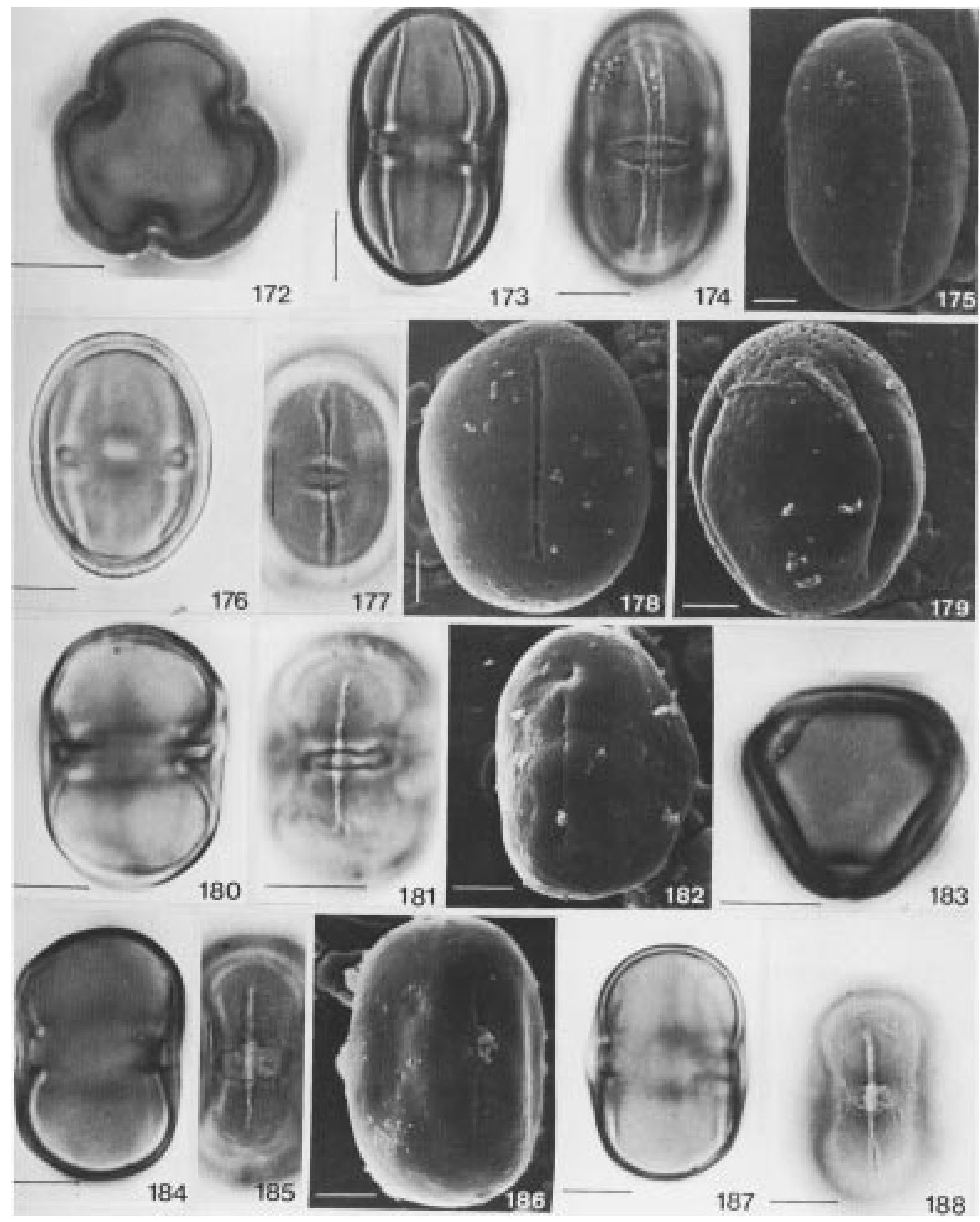

Figuras 172-188. Fotomicrografias e elétron-micrografias dos grãos de pólen de espécies de Protium. 172-175. P. subserratum. 172. Vista polar, âmbito pticotremado; 173-174. Vista equatorial, contorno (173), detalhe do cólporo, colpo longo, largo, com margem, endoabertura elíptica (174); 175. MEV: vista equatorial, sexina psilada (escala $=5 \mu \mathrm{m})$. 176-179. P. tenuifolium var. herbertii. 176-177. Vista equatorial, corte óptico (176), detalhe do cólporo (177); 178-179. MEV (escalas $=5 \mu \mathrm{m}$ ): vista equatorial, abertura (178), mesocolpo (179), sexina psilado-perfurada, perfurações mais conspícuas na região polar. 180-182. $P$. trifoliolatum. 180-181. Vista equatorial, corte óptico (180), detalhe do cólporo, endoabertura retangular (181); 182. MEV: vista equatorial, sexina psilada (escala $=5 \mu \mathrm{m}) ; 183-186$. P. unifoliolatum. 183. Vista polar, contorno; 184-185. Vista equatorial, corte óptico (184), detalhe do cólporo, endoabertura retangular (185); 186. MEV: vista equatorial, sexina psilada $($ scala $=5 \mu \mathrm{m}) ; 187-188$. P vestitum. Vista equatorial, corte óptico (187), cólporo, endoabertura retangular (188). Escala das fotomicrografias $=10 \mu \mathrm{m}$. 


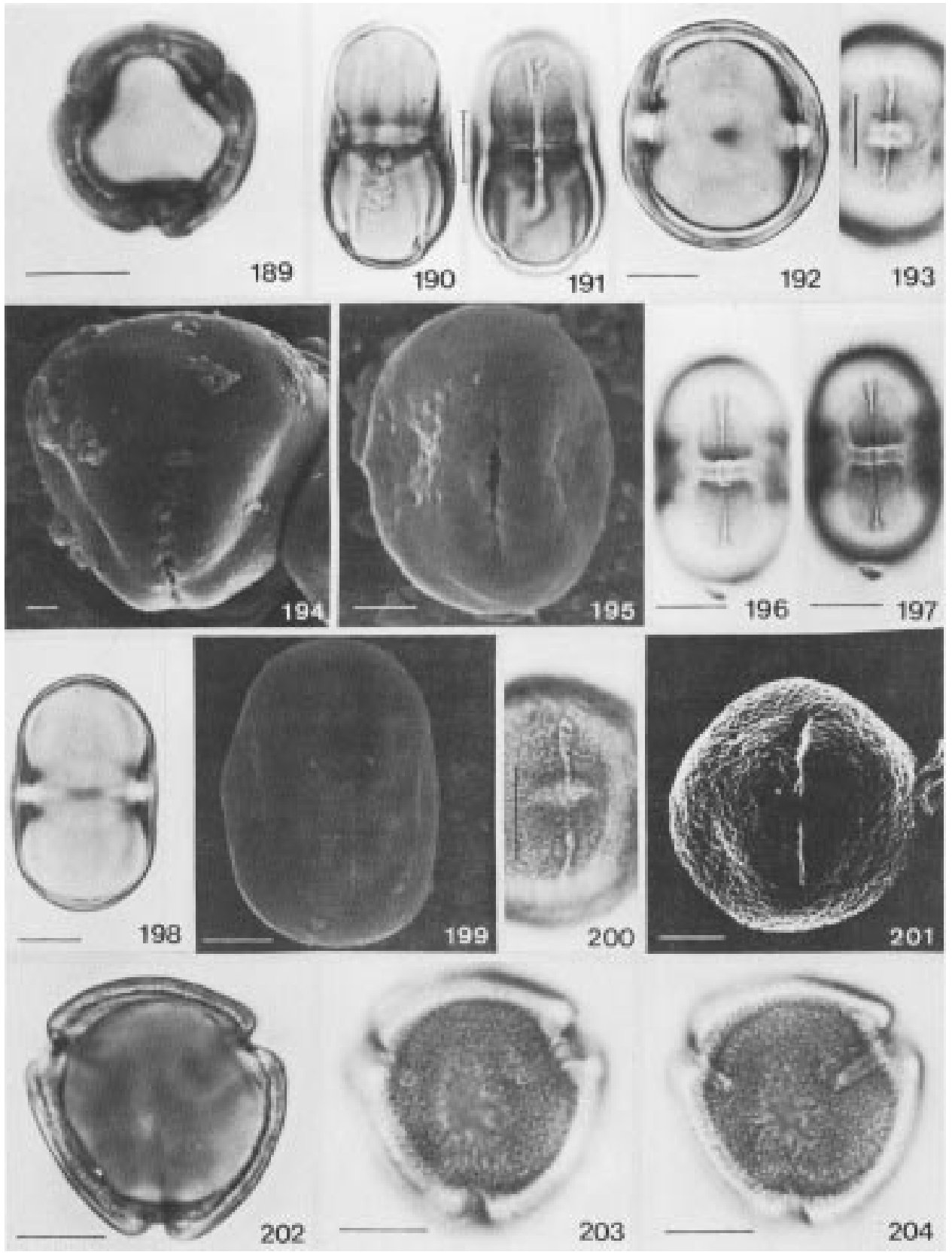

Figuras 189-204. Fotomicrografias e elétron-micrografias dos grãos de pólen de espécies de Protium sem identificação infra-específica. 189-191. P. divaricatum. 189. Vista polar, contorno; 190-191. Vista equatorial, contorno (190), cólporo, endoabertura retangular (191). 192-195. P. guianense. 192-193. Vista equatorial, corte óptico (192), detalhe da abertura, endoabertura retangular (193); 194195. MEV. 194. Região polar, sexina psilada (escala $=2 \mu \mathrm{m}$ ); 195. Vista equatorial, abertura, sexina com perfurações no mesocolpo (escala $=5 \mu \mathrm{m})$. 196-199. P. paniculatum. 196-197. Detalhe do cólporo em dois níveis de localização; 198. Vista equatorial, corte óptico; 199. MEV: vista equatorial, sexina psilada (escala $=5 \mu \mathrm{m}$ ); 200-204. P tenuifolium. 200. Detalhe do cálporo, endoabertura elíptica; 201. MEV. vista equatorial, sexina microrreticulada, muros ondulados (escala $=10 \mu \mathrm{m}$ ); 202. Vista polar, corte óptico; 203 204. Análise de L.O. mostrando a ornamentação microrreticulada. Escala das fotomicrografias $=10 \mu \mathrm{m}$. 
Apenas a observação de Harley (1991) que afirmou que Crepidospermum, junto com Canarium, Dacryodes, Protium, Tetragastris e Trattinnickia, apresenta grãos de pólen com o tipo de abertura mais freqüente na família, isto é, um colpo longo (3/4 a $5 / 6$ do comprimento do eixo polar), com endoabertura lalongada, provida de costa.

Do ponto de vista palinológico, as espécies de Crepidospermum aqui estudadas possuem grãos de pólen médios, com âmbito triangular e exina psilada; em geral, são subprolatos (exceto em $C$. prancei onde são prolatos), 3-colporados (raros grãos de pólen 2-colporados em $C$. prancei e $C$. rhoifolium), com a endoabertura lalongada, elíptica ou retangular; estas características indicam que se trata de um gênero estenopolínico. A abertura polínica é o único caráter que permite distinguir as espécies de Crepidospermum estudadas: o colpo é inconspícuo em $C$. cuneifolium; a endoabertura pseudo-sinclinorada em $C$. rhoifolium, elíptica em C. goudotianum e retangular em C. prancei.

As espécies de Tetragastris observadas, T. altissima e T. panamensis, revelaram uma grande similaridade na morfologia polínica, com grãos de pólen médios, prolatos, âmbito triangular, (2)-3-colporados, colpo longo, membrana do colpo granulada, endoabertura lalongada, retangular, com costa, sexina psilada. Embora os intervalos de confiança das medidas dos diâmetros polar e equatorial sejam diferentes no materiais padrão dos dois táxons, o tamanho não pode ser utilizado para separar estas espécies, pois a maioria dos dados obtidos nos materiais de comparação não confirmaram estes valores. Roubik \& Moreno (1991) caracterizaram os grãos de pólen de T. panamensis como tendo tamanho maior, âmbito semi-lobado a circular e exina psilada a suavemente estriada, características distintas daquelas encontradas nos espécimes de $T$. panamensis aqui estudados.

Forman et al. (1989) referem-se às observações de Dalley (não publicadas), quanto à similaridade dos grãos de pólen de Tetragastris, Garuga e Trattinnickia. Quando comparados os resultados aqui obtidos para Tetragastris e aqueles de Trattinnickia (Aguilar-Sierra \& Melhem 1998) é possível a distinção dos grãos de pólen de Tetragastris que são menores, com a exina mais fina e sem ornamentação (psilada ao MEV), enquanto em Trattinnickia a exina é granulada sob microscópio óptico e psilado-perfurada ao MEV. Com relação a
Garuga, Segaar \& van der Ham (1993), mostraram para G. floribunda Decaisne e G. pinnata Rox. que a exina é psilado-perfurada com o centro do mesocolpo indistintamente estriado. De acordo com os resultados deste trabalho e os de Aguilar-Sierra \& Melhem (1 998), verifica-se que há sobreposição nos caracteres polínicos dos gêneros Crepidospermum, Dacryodes, Protium e Tetragastris.

Segundo Daly (1992a), dentro de Protium podem ser identificados, pelo menos, nove grupos naturais, alguns dos quais têm sido tratados como seções e inclusive dois, Icica Aubl. e Icicopsis Engl., foram publicados originalmente como gêneros diferentes; este autor tem mantido, até agora, todos esses grupos em Protium devido à existência de uma série de caracteres comuns e à falta de outros que sejam únicos e que garantam o status genérico.

Do ponto de vista palinológico verificou-se que dentro do grupo com pólen psilado, sob microscopia óptica e ao $\mathrm{MEV}$, a maioria das espécies possui grãos de pólen médios, subprolatos ou prolatos $(\mathrm{P} / \mathrm{E}<1,70)$; a separação taxonômica poderia ser feita com base na forma da endoabertura retangular ou elíptica e no tamanho do diâmetro polar, significativamente maior em $P$. subserratum, táxon que também é distinto por seus grãos de pólen pticotremados. As espécies com exina lisa são palinologicamente similares, com exceção daqueles grãos de pólen longos $(\mathrm{P} / \mathrm{E} \geq 1,70)$, quase perprolatos $(P$. calanense, $P$. divaricatum subsp. fumarium e $P$. insigne), de contorno ligeiramente côncavo em vista equatorial (P. insigne) ou com endoaberturas pseudosinclinoradas (P. cf. leptostachyum e P. trifoliolatum); isto mostra o caráter estenopolínico deste grupo dentro de Protium.

As espécies $P$. llanorum e $P$. heptaphyllum, de acordo com Daly (comunicação pessoal), são próximas na sua morfologia, posicionamento este confirmado no presente trabalho. Carreira (1976) descreveu os grãos de pólen de $P$. heptaplyllum como pequenos, prolatos, âmbito triangular, 3-colporados, exina lisa, com báculos subtectais; verificou-se neste estudo que os grãos de pólen das oito exsicatas examinadas têm tamanho médio e forma, predominantemente, subprolata.

Quanto a P. aracouchini, Daly (1987b) afirmou que difere ligeiramente do resto do gênero, pelos grãos de pólen lisos a foveolados, com forma estreitamente elipsoidal e colpos longos, estendidos 
quase até os pólos; as observações aqui obtidas mostram que $P$. aracouchini tem grãos de pólen completamente psilados. Esta espécie é morfologicamente muito semelhante a $P$. calanense o que dificulta sua separação (Cuatrecasas 1957; Daly comunicação pessoal) e, segundo Swart (1942), está relacionada com $P$. elegans e esta com $P$. spruceanum. Verificouse que estas quatro espécies apresentam características morfopolínicas similares; Erdtman (1952) descreveu $P$. spruceanum (sob P. almecega March.) com grãos de pólen subprolatos, subpsilados e nexina notavelmente espessa nas aberturas. Cuatrecasas (1957) assinalou a afinidade de $P$. elegans com $P$. lepstostachyum; os resultados deste estudo mostram que a forma da endoabertura, elíptica e retangular pseudo-sinclinorada, respectivamente, permite a separação de seus grãos de pólen.

De acordo com Daly (1989), P. trifoliolatum é próxima a $P$. unifoliolatum; palinologicamente são distintas pela presença de endoabertura pseudosinclinorada apenas em $P$. trifoliolatum.

Um segundo grupo polínico, dentro do gênero Protium, estaria constituído por aquelas espécies com grãos de pólen médios, psilados sob microscopia óptica, psilado-perfurados ao MEV. Em P. amplum, $P$. cranipyrenum, $P$. ferrugineum e $P$. nervosum as perfurações são conspícuas, próximas umas das outras, exceto na área que circunda o cólporo onde a exina é psilada. O teto psilado entre as perfurações em $P$. ferrugineum distingue este táxon; nos demais, com o teto ondulado entre as perfurações, a endoabertura é retangular apenas em $P$. nervosum; em $P$. cranipyrenum é elíptica, constricta no centro (ca. 5,86 x 11,96 $\mu \mathrm{m}$ ) enquanto em $P$. amplum é elíptica, não constricta no centro (ca. 6,45 x 7,70 $\mu \mathrm{m})$. P. amplum, $P$. cranipyrenum e $P$. nervosum fazem parte da seção Icica (Aubl.) Engl. e na chave de espécies proposta por Cuatrecasas (1957), P. amplum e P. cranipyrenum estão contíguas; $P$. ferrugineum foi colocada por este autor dentro do gênero Paraprotium, junto com $P$. vestitum, $P$. nitidifolium e $P$. fimbriatum, posicionamento este que Daly (1989) considerou incorreto, o que a morfologia polínica confirma: os grãos de pólen de $P$. vestitum, médios, completamente psilados, não mostraram semelhanças com aqueles de $P$. nitidifolium e $P$. fimbriatum (pequenos, psilados em microcopia óptica e estriados ao MEV) nem com os de $P$. ferrugineum (médios, psilados em microscopia óptica e psilado-perfurados ao MEV).
Dentro deste grupo também foram observadas algumas espécies que apresentam as perfurações inconspícuas e esparsas, sendo possível estabelecer as seguintes diferenças: $P$. altsonii e $P$. tenuifolium var. herbertii com perfurações esparsas por toda a superfície; e $P$. paniculatum var. paniculatum com perfurações restritas ao apocolpo. Daly (1987b) descreveu os grãos de pólen deste último táxon como distintamente foveolados; verificou-se no presente trabalho que são perfurações com diâmetro $<1,00 \mu \mathrm{m}$ e por isso não podem ser denominadas de fovéolas.

Segundo Daly (1992a) a seção Sarcoprotium Daly, com $P$. carnosum como espécie-tipo, é a melhor definida e abrange táxons que compartilham caracteres exclusivos dentro do gênero. Desta seção foram aqui estudados os grãos de pólen de $P$. carnosum, $P$. crassipetalum, $P$. pedicellatum e $P$. rubrum; na literatura, há dados para $P$. polybotryum, cujos grãos de pólen foram descritos por Daly (1987b) como pequenos (diâmetro ca. 14,00 $\mu \mathrm{m}$ ), esféricos, ectoaberturas indistintas e sexina densamente baculada.

No presente estudo, é importante ressaltar aproximidade de $P$. carnosum, $P$. crassipetalum e $P$. rubrum, três espécies facilmente reconhecíveis dentro do gênero, pela forma esferoidal e pela ornamentação microrreticulada da exina sob microscopia óptica, o que confirma a estreita relação entre estes táxons. Sob MEV verificou-se que $P$. carnosum e $P$. crassipetalum apresentam espículos nos muros; em $P$. rubrum não foi possível estudar o pólen ao MEV por falta de material adequado; também é interessante destacar, em $P$. carnosum, a diferença no tamanho dos lúmens e dos muros do microrretículo, maiores na região polar do que na região equatorial. $\mathrm{O}$ tamanho do diâmetro polar é um caráter palinológico que permitiria diferenciar $P$. carnosum de $P$. crassipetalum e $P$. rubrum.

O único espécime de $P$. pedicellatum que foi estudado apresentou uma morfologia polínica muito diferente, com grãos de pólen médios, subprolatos, psilados, distintos de $P$. rubrum que, segundo Daly (1992a), pode ser sinônimo de $P$. pedicellatum. Apesar das diferenças polínicas detectadas, um posicionamento mais conclusivo fica na dependência de um estudo mais completo, com um número maior de espécimes. No momento, para cada táxon conseguiu-se apenas uma exsicata.

Também foram observados grãos de pólen microrreticulados, sob microscopia óptica, em $P$. 
divaricatum subsp. divaricatum, $P$. neglectum e $P$. sagotianum. $P$. divaricatum subsp. divaricatum destacou-se por apresentar exina microrreticulada com muros ondulados (MEV), enquanto em $P$. neglectum esta é psilado-perfurada (MEV). Nesta última espécie chegou-se à conclusão da necessidade de estudos mais completos ao MET a fim de compatibilizar os resultados obtidos sob microscopia óptica e ao MEV. Em $P$. sagotianum notou-se a presença de lúmens maiores dispersos pela superfície do pólen; Daly (1987b) descreveu os grãos de pólen desta espécie como distintamente foveolados, sendo verificado neste estudo que os lúmens não têm 1,00 $\mu \mathrm{m}$ de diâmetro e correspondem a perfurações.

O último grupo é caracterizado pela exina com ornamentação indefinida ou psilada, sob microscopia óptica, e estriada ao MEV. Ornamentação indefinida ocorre em $P$. apiculatum e $P$. minutiflorum, cujos grãos de pólen, sob MEV, apresentam estrias distintas entre si; em $P$. fimbriatum, $P$. cf. gallosum e $P$. nitidifolium a exina é psilada. A semelhança polínica destas espécies corresponde, em parte, à afinidade taxonômica que, de acordo com Daly (1989), existe entre $P$. apiculatum, $P$. fimbriatum e $P$. nitidifolium. O tamanho da endoabertura e a organização das estrias são características que podem ser usadas na separação dos táxons; o padrão de estrias longas, mais ou menos paralelas no mesocolpo, de P. minutiflorum contrastou com as estrias curtas, imbricadas, observadas nas outras quatro espécies. Daly (1987b) descreveu os grãos de pólen de $P$. apiculatum, $P$. fimbriatum, $P$. obtusifolium (Lam.) March. e $P$. plagiocarpium Benoist como prolatos, com ectoaberturas longas e escultura irregularmente estriada (não paralela); considerou $P$. apiculatum e $P$. fimbriatum como estreitamente relacionadas, proximidade que é confirmada pela similaridade polínica.

Os dados deste trabalho mostram para Protium uma grande variabilidade na forma dos grãos de pólen (esféricos, prolato-esferoidais, subprolatos, prolatos) e na ornamentação da exina (psilada, psilado-perfurada, estriada, microrreticulada); com freqüência observou-se variações no número de aberturas dentro de uma mesma exsicata e, muitas vezes, grãos de pólen loxocolporados, ou seja, com os colpos convergindo aos pares. A ornamentação da exina sob microscopia óptica e sob MEV, as medidas do diâmetro polar, a forma e o tamanho da endoabertura, o tamanho do colpo, a ornamentação da membrana do colpo e a espessura da exina são características que permitem diferençar entre si muitas das espécies consideradas. Estas observações confinam que Protium é um gênero euripolínico, de modo que a morfologia polínica pode, em muitos casos, subsidiar a delimitação das espécies.

\section{Referências bibliográficas}

AGUILAR-SIERRA, C.I. 1995. Contribuição à palinotaxonomia de Burseraceae. Tese de doutorado, Universidade de São Paulo, São Paulo.

AGUILAR-SIERRA, C.I. \& MELHEM, T.S. 1998. Morfologia polínica da tribo Canarieae (Burseraceae) na América do Sul. Revta brasil. Bot. 21:27-34.

BARROS, M.A. \& BARTH, O.M. 1994. Catálogo sistemático do pólen das plantas arbórcas do Brasil Meridional. XXVIII Burseraceae e Clethraceae. Revta. brasil. Biol. 54:317-322.

CARREIRA, L.M.M. 1976. Morfologia polínica de plantas lenhosas da campina. Acta Amazônica 6:247-269.

CUATRECASAS, J. 1957. Prima Flora Colombiana. 1. Burseraceae. Webbia 12:375-441.

DALY, D.C. 1987a. Studies in neotropical Burseraceae. I. A synopsis of the genus Crepidospermum. Brittonia 39:51-58.

DALY, D.C. 1987b. A taxonomic revision of the genus Protium (Burseraceae) in eastern Amazonia and the Guianas. Ph.D. dissertation, City University of New York, New York.

DALY, D.C. 1989. Studies in neotropical Burseraceae. II. Generic limits in New World Proticae and Canaricae. Brittonia 41: 17-27.

DALY, D.C. 1990. The genus Tetragastris and the forests of eastern Brazil. Studies in neotropical Burseraceae III. Kew Bull. 45:179-194.

DALY, D.C. 1992a. New taxa and combinations in Protium Burm. F. Studies in neotropical Burseraceae VI. Brittonia 44:280-299.

DALY, D.C. 1992b. Two new taxa of Protium from eastern Brazil. Studies in neotropical Bursercaeae V. Kew Bull. 47:713-719.

ERDTMAN, G. 1952. Pollen morphology and plant taxonomyangiosperms. Almqvist \& Wiksell, Stockholm.

ERDTMAN, G. 1960. The acetolysis method. A revised description. Svensk Bot. Tidskr. 54:561-564.

FORMAN, L.L., BRANDHAM, P.E., HARLEY, M.M. \& LAWRENCE, T.J. 1989. Beiselia mexicana (Burseraceae) and its affinities. Kew Bull. 44:1-31.

HARLEY, M.M. 1991. The pollen morphology of the Sapotaceae. Kew Bull. 46:379-491.

ROUBIK, D.W. \& MORENO, J.E. 1991. Pollen and spores of Barro Colorado Island. Monogr. Syst. Bot. Missouri Bot. Gard. 36:73-74.

SEGAAR, P.J. \& VAN DER HAM, R.W.J.M. 1993. Pollen of Scutinanthe brunnea compared with other Burseraceous pollen types: a remarkable case of divergence. Rev. Palaeobot. Palynol. 79:297-334.

SWART, J.J. 1942. A monograph of the genus Protium and some allied genera (Burseraceae). Rec. Trav. Bot. Néerl. 39:211-433. 